\title{
Measuring Economies of Vertical Integration in Network Industries: An Application to the Water Sector*
}

\author{
Serge Garcia $†$ Michel Moreaux; Arnaud Reynaud ${ }^{\ddagger}$
}

July 28, 2006

\begin{abstract}
This paper provides a framework that aims at distinguishing the technological economies of vertical integration from the vertical economies resulting from an inefficient input allocation due to upstream market imperfections. To illustrate our analysis, we use consistent panel data econometric methods to estimate cost functions on a sample of North-American water utilities. Contrary to what has been found for other network industries (electricity and gas for instance), we show that the global and technological economies of vertical integration are not significant except for the smallest utilities.
\end{abstract}

Keywords: Vertical integration, water network, cost function, panel data.

JEL Codes: C33, L22, L95.

\footnotetext{
${ }^{*}$ The authors would like to thank Stephen Martin and the two anonymous referees for helpful comments. We are very grateful to Patrick Rey and Thibaud Vergé for helpful discussions on a preliminary draft. We also would like to thank participants at the 2004 North American Summer Meeting of the Econometric Society at Brown University, at the CRDE seminar in Montréal and at the 2003 Applied Microeconomics Conference in Montpellier.

${ }^{\dagger}$ INRA, LEF, 14 rue Girardet, CS 14216, Nancy, F-54042 France; ENGREF, 14 rue Girardet, CS 14216, Nancy, F-54042 France; e-mail: garcia@nancy-engref.inra.fr. Preliminary versions of this paper was written when the author was a Postdoctoral Fellow at CIRANO, then a researcher in the Laboratory GEA.

${ }^{\ddagger}$ Université de Toulouse I (IUF, IDEI and LERNA), Manufacture des Tabacs - Bât.F, 21 allée de Brienne, F-31000 Toulouse, e-mail: mmoreaux@toulouse.inra.fr.

${ }^{\S}$ Université de Toulouse I (LERNA), Manufacture des Tabacs - Bât.F, 21 allée de Brienne, F-31000 Toulouse, tel: (33)-5-61-12-85-12, fax: (33)-5-61-12-85-20, e-mail: areynaud@toulouse.inra.fr. Corresponding author.
} 


\section{Introduction}

Unprecedented transformations aiming at introducing more competition into sectors traditionally considered as natural monopolies have been an important feature of public policy in the two last decades. One of the key recommendations of policy-makers has been to break up monopolies before introducing more competition. ${ }^{1}$ Behind this recommendation is the idea that natural monopoly and potentially competitive parts of a utility should be separated to prevent competition distortions. In most network industries, the result has been to introduce competition at the production stage while maintaining transmission and, in some cases, distribution as local monopolies.

However, it has been recently argued that vertical disintegration of utilities can result in cost efficiency losses if production stages are characterized by strong economies of vertical integration. ${ }^{2}$ Identifying the determinants of economies of vertical integration (EVI) is however not straightforward. EVI may be first the consequence of market imperfections and monopoly power at the upstream stages of the production process: if there are market imperfections, input allocation at the downstream stage will be distorted resulting in higher costs. But a vertically integrated structure can also be a cost effective solution if there are substantial needs for coordination and adaptation across stages. This may occur if there are significant technological complementarities across production stages or if using intermediate markets involves high transaction costs.

A global measure of economies of vertical integration, as proposed by Kaserman and Mayo (1991) or Kwoka (2002), does not permit distinguishing the technological and transactional economies from those resulting from an inefficient allocation of inputs due to market imperfections at an upstream stage. Yet, identifying the sources of EVI may be crucial in some cases. In particular, disintegration may only be cost effective if upstream markets are competitive enough. A regulatory authority should then promote a vertically disintegrated structure only if price distortions on the upstream markets can be limited. The conclusion given by a global measure of vertical integration could be subject to controversy in such a case. For network industries (e.g.

\footnotetext{
${ }^{1}$ The question of liberalization of these industries, its economic implications and political issues are also in the core of the structural reforms in the EU, see European Commission (1999).

${ }^{2}$ Interestingly, most of the empirical studies trying to assess the presence of economies of vertical integration have reported substantial cost efficiency gains for vertically integrated structures. Working on a sample of US electric utilities, Kaserman and Mayo (1991) have shown that the cost is on average 11.96 percent higher for vertically disintegrated services than for vertically integrated ones. Also working on a sample of US electric utilities, Kwoka (2002) concludes that disintegration may result in a substantial cost increase, 42 percent on average. Two recent studies suggest however that the economies of vertical integration might be lower. Nemoto and Goto (2004) using a panel of 9 Japanese utilities observed from 1981 to 1998, report a cost efficiency gain for the vertically integrated structure between 0.13 and 2.97 percent. Last, Jara-Díaz et al. (2004) based on a sample of Spanish electric utilities, conclude that joint generation and distribution may save $6.5 \%$ of costs.
} 
electricity, water, gas) characterized by strong technological interdependencies between production and distribution stages, identifying the source of EVI is particularly important. Recently, Nemoto and Goto (2004) have proposed a framework to estimate those technological externalities by introducing the capital stock of the upstream stage into the downstream stage cost function. Whereas this econometric study is the first to be explicit about the sources of EVI, it however does not take account of market imperfections as a potential source of EVI. By separately estimating the cost functions of vertically integrated and non-vertically integrated structures and by imposing marginal cost pricing on the upstream market, we make possible the distinction between the two sources of EVI.

Within network industries, the water sector seems to be a special case in which direct competition and production stage separation have not yet really been observed. ${ }^{3}$ Water utilities are still viewed as natural monopolies that must be regulated by public authorities. This is quite surprising as there are important similarities between water and the other network utilities where competition has been successfully introduced. ${ }^{4}$ As in gas and electricity, the production stage of the industry seems potentially competitive whereas the distribution stage presents some characteristics of a natural monopoly. The network of pipes is naturally monopolistic like the networks of pipes in gas and wires in electricity. So there is no obvious reason for limiting competition in any part of the production process which does not appear to be a natural monopoly, except if EVI are important. But as no measure of such economies have been yet published there is still no clear answer to the optimal organization of the water industry. One objective of this paper is to shed some light on this debate by providing an estimate of the EVI in the water industry.

The paper is organized as follows. In the next section, we discuss the nature of the EVI in network industries with a special emphasis on the water sector. Then, we present the cost model from which we derive the global and technological measures of the EVI. In the following section, we describe the database and our investigation area. Last, we present the result of the empirical application and we show that there are no significant global economies of vertical integration except for small water utilities. We also demonstrate that the technological economies are quite low in the water network industry.

\footnotetext{
${ }^{3}$ England is a special case. The 1998 Competition Act has opened up the scope for more competition in water industry. Inset appointments which allow the existing regulated water utility to be replaced by another for a specific site are now authorized. Common carriage which occurs when one service supplier shares the use of another's assets is also authorized by OFWAT.

${ }^{4}$ There are also important differences between networks but they cannot explain by themselves the absence of competition. For instance, it is claimed that the absence of competition could be related to the lack of a long-distance grid in water. But this lack can be the result of no competition in the past since incentives to connect to other monopolists' systems are minimal with captive consumers.
} 


\section{Structure of production and vertical integration}

\subsection{The nature of economies of vertical integration}

If an industry is characterized by several successive production stages, ${ }^{5}$ a single firm may be able to produce the complementary products of these different stages more efficiently than would several firms. Such industries present, at some stages, EVI, i.e. the total cost of producing is lower in a vertically integrated structure than in a disintegrated one. Sources of EVI, although difficult to identify, can be classified into three main categories: technological economies, transactional economies and economies resulting from an inefficient input allocation due to upstream market imperfections.

First, vertical integration may be a cost effective solution in the presence of technological economies. These technological economies come from physical interdependencies in the production process. There are technological economies if there are economies of scope across different production stages, that is if there are important complementarities or coordination economies across stages. These coordination economies include a greater adaptability to non-anticipated events and better information for taking a decision that will have an effect at different production steps. Typically, in networks, joint optimization of production plant capacity and the size of the transmission system will lead to technological economies. Costs can also be reduced if integration of firms results in a closer geographic proximity of production units. Finally, vertical integration can facilitate investment in specialized assets by making it possible to avoid the holdup problem. One important drawback of vertical integration is that it may decrease flexibility. Moreover, vertical integration raises some capacity balancing issues. In the absence of alternative input sources, the integrated firm may be compelled to build excess upstream capacity to meet the downstream demand in all conditions.

Transactional economies, associated with the use of intermediate product markets, may be another important determinant of vertical integration. The transaction costs mainly correspond to coordination costs, i.e., to cost reflecting the design, the negotiation and the enforcement of contracts between buyers and sellers. Transaction costs also involve costs related to asset specificity, to the incomplete nature of contracts and to the problem of asymmetric information. Transactional economies may come from a reduction in opportunistic behavior in bilateral exchange, and from an efficient conflict resolution machinery, Williamson (1985). However, an

\footnotetext{
${ }^{5}$ We may think to the usual distinction between production, transmission and distribution in the electric industry or in the telecommunication networks.
} 
important limit to the presence of transactional economies is the size of the vertically integrated structure. Large integrated firms will result in important internal incentive problems. This is especially the case if the managerial objectives at each production stage are not aligned with the overall objective. In a vertical setting, a subordinate manager may have lower incentives to come up with good ideas to reduce production costs, as this investment may by expropriated by the firm's owner, Grossman and Hart (1986). Hence, transactional economies will exist if the coordination gains outweigh the internal incentive costs.

Other driving forces of vertical integration are market imperfections. In particular, if there are important scale economies at the production stage, the upstream firms may benefit from large profit margins. This will result in an inefficient combination of inputs at the downstream stage. Cost efficiency may favor a vertically integrated structure in such a case. However, vertical integration, by aggregating monopoly positions may lead to the need for a heavier form of regulation, especially for protecting final customers. Moreover, vertical integration may result in a foreclosure problem. Foreclosure refers to a dominant firm's denial of proper access to an essential good in order to extend monopoly power from one market to another, see Hart et al. (1990) or Rey and Tirole (2003). The foreclosure issue does not seem to be the main market imperfection problem for the water sector, since water suppliers usually operate on geographicly separated markets.

In assessing the optimal degree of vertical integration in a network industry, it is important to distinguish the technological economies (non duplication of fixed costs, better coordination, ...), that favor a vertically integrated industry from those resulting from price distortions on markets for intermediate goods, that may favor vertically separated firms. It is crucial to separate and identify these two issues as it is clear that the welfare consequences of vertical integration will depend upon the motivation for vertical integration. Integration to take advantage of technological vertical economies will, other things equal, improve welfare.

\subsection{Vertical integration in the water network industry}

Vertically-integrated water utilities are still the norm in most countries. There are two main reasons for the persistence of such market structures. First, an important characteristic of water supply services is that they are local: the production plant and the distribution network are often very close (mainly because of network losses and alteration of the water quality during transportation). Second, quality is essential and introducing multiple water suppliers in the same distribution network may create some difficulties, Bisshop (2001). These difficulties include 
the compatibility of water treatments realized by different producers, the origin of water in the network, or the liability in case of sanitary problems.

Coordination between the delivery service and producers is also important, especially for the volume of water that must be injected into the network. The distribution stage may require additional water flow from the production stage in order to compensate for a low rate of network return or to adapt deliveries to peak-load demand. Each stage of the water supply process (production and distribution) is also constrained by pressurization facilities. Once again, good coordination between the two stages is necessary to maintain a sufficient pressure at the taps of users. Other problems can arise depending on whether the network is meshed or in arborescence. In the first case, the water can circulate in all directions. In the second case, water flows thanks to gravity and the production stage must be located upstream.

\subsection{Measuring economies of vertical integration in a multi-stage industry}

Several studies (mostly focusing on the electric sector) have tried to assess the level of the EVI using different frameworks. First, some authors (Lee, 1995, Hayashi et al., 1997) have tested the cost separability of the different production stages. The issue addressed by these authors is in fact to test whether input proportions used to produce the final output depend or not on the price of the intermediate good. As noted by Kwoka (2002), this indirect test does not allow to properly measure the EVI.

Kaserman and Mayo (1991) have proposed to measure the EVI by evaluating the economies of scope in a multiproduct cost framework. The idea is that a fully vertically-integrated utility produces all stage outputs. By nullifying one output, the production cost specific to this output can be assessed. In a two-stage production process, Kwoka (2002) has adapted this framework in order to properly compare the costs of an integrated utility with the cost of a pure-distribution utility.

Three major drawbacks emerge from this measure of the EVI. First, this approach requires estimation of a single cost function. The implicit assumption is that the data generating process of the cost of a utility does not depend on the vertical organization of the sector. In other words, it is assumed that the production technology and the estimated parameters are identical whether the firm is integrated, a pure-production utility or a pure-distribution utility. But this implicit assumption is not likely to hold as the production technology may strongly differ with the vertical organization and hence so may the cost-minimizing programs of the different utilities. Second, the measure of EVI proposed by Kaserman and Mayo (1991) and Kwoka (2002) 
is a global measure that does not allow distinguishing between technological determinants and input allocation distortions resulting from market imperfections. Last, because the definition of economies of scope involves zero output at some stage, using a translog cost function is not possible. Previous studies have estimated a quadratic cost function that imposes some constraints, making the approximation of the cost function less flexible. ${ }^{6}$ For these reasons, we propose to estimate a cost function specific to each type of utility. This requires us to estimate a cost function for a vertically-integrated (VI) utility and cost functions for all types of nonvertically integrated (NVI) services.

Still in the electric utility context, Nemoto and Goto (2004) have recently proposed to measure technological externalities by testing if the cost function of the transmission-distribution stage depends upon the capital used at the generation stage. This is a strong assumption since technological EVI may potentially have many other sources (for instance some variable inputs used at the upstream stage may also be used at the downstream stage, some economies of coordination between stages may also not depend upon the level of capital, etc.). Moreover, Nemoto and Goto (2004) estimate only a distribution cost function and do not consider the effect of market imperfections as a potential motive for vertical integration. ${ }^{7}$

\subsubsection{Cost structure for a vertically-integrated utility}

In order to simplify the presentation of the model we consider a firm characterized by two vertically related production stages, indexed by $s=1,2$ and called the production and the distribution stage, respectively. The cost model can easily be extended to a higher number of successive stages.

At stage $s$, the utility uses a vector $X_{s}$ of $k_{s}$ inputs and we denote by $Z_{s}$ the capital and technical variables of the corresponding stage. We let $Y_{1}$ denote the intermediate output produced at the first stage, $Y_{2}$ the final output produced at the second stage, and $g$ the production function

\footnotetext{
${ }^{6}$ The main limitation of the quadratic functional form is that it is not linearly homogeneous in input prices. Such a property can be imposed on the translog form through a set of parameter constraints, but this cannot be done in the quadratic case without loosing its flexibility (Caves et al., 1980). Moreover, the translog function allows the analysis of the underlying production structure (homogeneity, separability, economies of scale, etc.) through simple tests on estimated parameters and the first order coefficients can be directly interpreted as costproduct elasticities (at the approximation point). Last, the number of parameters to be estimated is larger for the quadratic function than for the translog thanks to constraints imposed on the translog function (such as homogeneity in factor prices and symmetry).

${ }^{7}$ Moreover, Nemoto and Goto (2004) model the electricity input received from the production stage as being quasi-fixed at the transmission-distribution stage. Instead, we propose to introduce the relationship between the two stages through the price of water sold by the production to the distribution stage. Identification of technical EVI is then made possible by equalizing the water price to the marginal cost of the production stage, which depends among other things on the production stage capital stock. Hence, our proposed measure of technological EVI implicitly takes into account all technical characteristics of the production stage, including the capital level.
} 
of the VI utility. ${ }^{8}$ The overall cost minimization program of the VI utility can be written:

$$
\min _{X_{1}, X_{2}} \sum_{k_{1}} w_{1 k_{1}} \times X_{1 k_{1}}+\sum_{k_{2}} w_{2 k_{2}} \times X_{2 k_{2}} \quad \text { s.t. } \quad Y_{2}=g^{v i}\left(X_{1}, X_{2} \mid Z_{1}, Z_{2}\right)
$$

where $w_{1}$ and $w_{2}$ are the factor prices of stages 1 and 2 respectively.

The overall cost function of the VI utility is:

$$
C^{v i}\left(Y_{2}, w_{1}, w_{2} \mid Z_{1}, Z_{2}\right)
$$

Cost minimization requires equalization of the relative marginal productivity of inputs at each stage, and also across the two successive stages. Equalization of relative marginal productivity of inputs across stages is specific to a vertically integrated structure.

\subsubsection{Cost structure for non-vertically integrated utilities}

Let us assume now that the two stages are not integrated. The gross output $Y_{1}$ is produced by a utility (production utility) and $f_{1}$ is the associated production function. Then $Y_{1}$ is sold to another separated utility (distribution utility) which uses it as an input of the distribution stage with the production function $f_{2}$.

We first consider the production utility, $s=1$. The cost minimization program can be written:

$$
\min _{X_{1}} \sum_{k_{1}} w_{1 k_{1}} \times X_{1 k_{1}} \quad \text { s.t. } \quad Y_{1}=f_{1}^{n v i}\left(X_{1} \mid Z_{1}\right)
$$

The non-vertically integrated production (NVI production) cost function is:

$$
C_{1}^{n v i}\left(Y_{1}, w_{1} \mid Z_{1}\right)=\sum_{k_{1}} w_{1 k_{1}} \times \widehat{X}_{1 k_{1}}^{n v i}\left(Y_{1}, w_{1} \mid Z_{1}\right)
$$

where $\widehat{X}_{1}^{n v i}\left(Y_{1}, w_{1} \mid Z_{1}\right)$ represent the input derived demands.

Cost minimization at the production stage requires equalization of the relative marginal productivity of inputs used at this stage.

Now we consider a distribution utility that must buy the intermediate good $Y_{1}$ at a unit price

\footnotetext{
${ }^{8}$ In the water network industry, $Y_{1}$ and $Y_{2}$ represent the volume of water respectively withdrawn and sold to final users.
} 
$w_{Y_{1}}$. For such a distribution utility, the cost minimization program can be written:

$$
\min _{Y_{1}, X_{2}} w_{Y_{1}} Y_{1}+\sum_{k_{2}} w_{2 k_{2}} \times X_{2 k_{2}} \quad \text { s.t. } \quad Y_{2}=f_{2}^{n v i}\left(Y_{1}, X_{2} \mid Z_{2}\right) .
$$

The non-vertically integrated distribution (NVI distribution) cost function is:

$$
C_{2}^{n v i}\left(Y_{2}, w_{Y_{1}}, w_{2} \mid Z_{2}\right)=w_{Y_{1}} \times \widehat{Y}_{1}^{n v i}\left(Y_{2}, w_{Y_{1}}, w_{2} \mid Z_{2}\right)+\sum_{k_{2}} w_{2 k_{2}} \times \widehat{X}_{2 k_{2}}^{n v i}\left(Y_{2}, w_{Y_{1}}, w_{2} \mid Z_{2}\right)
$$

where $\widehat{X}_{2}^{n v i}\left(Y_{2}, w_{Y_{1}}, w_{2} \mid Z_{2}\right)$ is the derived demand in second stage inputs and $\widehat{Y}_{1}^{n v i}\left(Y_{2}, w_{Y_{1}}, w_{2} \mid Z_{2}\right)$ the derived demand in intermediate good.

Cost minimization at the distribution stage requires equalization of the relative marginal productivity of inputs used at this stage. These inputs include the intermediate good, $Y_{1}$. The VI and the NVI structures are equivalent if and only if the two following conditions are satisfied:

$$
\begin{gathered}
w_{Y_{1}}=\frac{\partial}{\partial Y_{1}} C_{1}^{n v i}\left(Y_{1}, w_{1} \mid Z_{1}\right) \\
g^{v i}\left(X_{1}, X_{2} \mid Z_{1}, Z_{2}\right)=f_{2}^{n v i}\left(f_{1}^{n v i}\left(X_{1} \mid Z_{1}\right), X_{2} \mid Z_{2}\right),
\end{gathered}
$$

that is if the intermediate good in a (non-vertically integrated) production utility is priced at its marginal production cost and if the production function of the VI structure can be decomposed into the two successive NVI stages. As we do not impose condition (5), we take into account the possibility that being vertically integrated or not may result in different technologies of production (due for instance to the specificity of assets or the need to solve internal incentive problems in the vertically integrated case).

Finally, the overall cost for a NVI structure is equal to the variable cost of the production and the distribution stages less the intermediate good expenses of the distribution utility. These expenses correspond, in fact, to a monetary transfer from the distribution utility to the production utility that cancel out when considering the whole vertical structure. Moreover, as the produced volume $Y_{1}$ supplied to the distribution utility corresponds to the optimal derived demand in intermediate good of the distribution utility $\widehat{Y}_{1}^{n v i}\left(Y_{2}, w_{Y_{1}}, w_{2} \mid Z_{2}\right)$, the overall cost for a 
NVI structure is:

$$
\begin{aligned}
C^{n v i}\left(Y_{2}, w_{Y_{1}}, w_{1}, w_{2} \mid Z_{1}, Z_{2}\right)= & C_{1}^{n v i}\left(\widehat{Y}_{1}^{n v i}\left(Y_{2}, w_{Y_{1}}, w_{2} \mid Z_{2}\right), w_{1} \mid Z_{1}\right)+C_{2}^{n v i}\left(Y_{2}, w_{Y_{1}}, w_{2} \mid Z_{2}\right) \\
& -w_{Y_{1}} \times \widehat{Y}_{1}^{n v i}\left(Y_{2}, w_{Y_{1}}, w_{2} \mid Z_{2}\right) \\
= & \sum_{k_{1}} w_{1 k_{1}} \times \widehat{X}_{1 k_{1}}^{n v i}\left(\widehat{Y}_{1}^{n v i}\left(Y_{2}, w_{Y_{1}}, w_{2} \mid Z_{2}\right), w_{Y_{1}}, w_{1}, w_{2} \mid Z_{1}, Z_{2}\right) \\
& +\sum_{k_{2}} w_{2 k_{2}} \times \widehat{X}_{2 k_{2}}^{n v i}\left(Y_{2}, w_{Y_{1}}, w_{2} \mid Z_{2}\right) .
\end{aligned}
$$

\subsubsection{Economies of vertical integration}

A direct comparison of $C^{v i}$ and $C^{n v i}$ allows us to measure the global economies of vertical integration, that is economies of integration resulting from both technological effects and from an inefficient input allocation. ${ }^{9}$ The global economies of vertical integration $(G V I)$ are measured by the ratio:

$$
\mathrm{GVI}=\frac{C^{v i}\left(Y_{2}, w_{1}, w_{2} \mid Z_{1}, Z_{2}\right)}{C^{n v i}\left(Y_{2}, w_{Y_{1}}, w_{1}, w_{2} \mid Z_{1}, Z_{2}\right)}
$$

If $G V I<1$ then the vertical structure is characterized by global economies of vertical integration. In other words, given the level of final output to be produced $Y_{2}$, the price of inputs $\left(w_{1}, w_{2}\right)$ and the price of the intermediate good $w_{Y_{1}}$, a vertically integrated structure will produce at a lower cost. On contrary, if $G V I>1$, there are diseconomies of vertical integration and two separated utilities are more efficient. Finally, if $G V I=1$, there are neither economies nor diseconomies of vertical integration.

As mentioned previously, such a measure of economies of vertical integration mixes the technological effects (interdependence between the two stages in the case of integrated structure and asset specialization in the case of non-integrated structure for instance) with the market effects (noncompetitive market for intermediate good resulting in a nonefficient allocation of inputs at the second stage). In order to identify these market and technological effects, we propose the following approach: first we compute the total cost of a non-vertically structure while imposing that the intermediate good to be sold at its marginal production cost and, second we compare this cost to the cost of a vertically integrated structure.

First, we consider the NVI production utility. Following equation (2), the cost function is $C_{1}^{n v i}\left(Y_{1}, w_{1} \mid Z_{1}\right)$. Let us assume that the intermediate good is sold at its marginal production

\footnotetext{
${ }^{9}$ It is clear that if the vertical organization choice is not random, such a direct comparison will suffer from a sample selection bias. A consistent estimation of the cost functions requires in such a case to control for differences inducing the vertical organization choice. We will more formally address this issue in the empirical part of this article.
} 
cost. In this case following equation (4) we have:

$$
w_{Y_{1}}=\frac{\partial}{\partial Y_{1}} C_{1}^{n v i}\left(Y_{1}, w_{1} \mid Z_{1}\right)
$$

As the right hand-side of this equation depends upon $Y_{1}$, the unit price for the intermediate good will be a complex function of the quantity. It is important to notice that this condition does not necessary mean that the market for the intermediate good is assumed to be perfectly competitive. A fixed charge may be used by the production utility to recover losses in case of increasing returns to scale. But in that case, the fixed charge does not have any effect on input allocation at the distribution stage, and what really matters is the marginal price. The fixed charge is just a transfer from the distribution utility to the production utility that will cancel out when evaluating the total cost of the NVI structure. Condition (8) defines the price of the intermediate good as a function of the first-stage output and first-stage input prices:

$$
w_{Y_{1}}=w_{Y_{1}}\left(Y_{1}, w_{1} \mid Z_{1}\right) .
$$

Let us now consider the NVI distribution utility. The derived demand for $Y_{1}$ is $\widehat{Y}_{1}^{n v i}\left(Y_{2}, w_{2}, w_{Y_{1}} \mid Z_{2}\right)$, see equation (3). Marginal cost pricing at the first stage gives:

$$
\widetilde{Y}_{1}^{n v i}\left(Y_{2}, w_{1}, w_{2} \mid Z_{1}, Z_{2}\right)=\widehat{Y}_{1}^{n v i}\left(Y_{2}, w_{2}, w_{Y_{1}}\left(Y_{1}, w_{1} \mid Z_{1}\right) \mid Z_{2}\right)
$$

The total cost, net of the intermediate good purchase cost, for a NVI distribution utility with marginal cost pricing at the first stage, is:

$$
\begin{aligned}
\sum_{k_{2}} w_{2 k_{2}} \times \widehat{X}_{2 k_{2}}^{n v i}\left(Y_{2}, w_{2}, w_{Y_{1}} \mid Z_{2}\right) & =\sum_{k_{2}} w_{2 k_{2}} \times \widehat{X}_{2 k_{2}}^{n v i}\left(Y_{2}, w_{2}, w_{Y_{1}}\left(Y_{1}, w_{1} \mid Z_{1}\right) \mid Z_{2}\right) \\
& =\sum_{k_{2}} w_{2 k_{2}} \times \widehat{X}_{2 k_{2}}^{n v i}\left(Y_{1}, Y_{2}, w_{1}, w_{2} \mid Z_{1}, Z_{2}\right) \\
& =\sum_{k_{2}} w_{2 k_{2}} \times \widehat{X}_{2 k_{2}}^{n v i}\left(\widetilde{Y}_{1}^{n v i}\left(Y_{2}, w_{1}, w_{2} \mid Z_{1}, Z_{2}\right), Y_{2}, w_{1}, w_{2} \mid Z_{1}, Z_{2}\right) \\
& =\widetilde{C}_{2}^{n v i}\left(Y_{2}, w_{1}, w_{2} \mid Z_{1}, Z_{2}\right) .
\end{aligned}
$$

Using equations (2) and (10), the cost function of the NVI producer utility is a function of $Y_{2}$, 
$w_{1}, w_{2}, Z_{1}$ and $Z_{2}$ :

$$
\widetilde{C}_{1}^{n v i}\left(Y_{2}, w_{1}, w_{2} \mid Z_{1}, Z_{2}\right)=C_{1}^{n v i}\left(\widetilde{Y}_{1}^{n v i}\left(Y_{2}, w_{1}, w_{2} \mid Z_{1}, Z_{2}\right), w_{1} \mid Z_{1}\right)
$$

The overall cost of a NVI structure, imposing condition (8), is:

$$
\widetilde{C}^{n v i}\left(Y_{2}, w_{1}, w_{2} \mid Z_{1}, Z_{2}\right)=\widetilde{C}_{1}^{n v i}\left(Y_{2}, w_{1}, w_{2} \mid Z_{1}, Z_{2}\right)+\widetilde{C}_{2}^{n v i}\left(Y_{2}, w_{1}, w_{2} \mid Z_{1}, Z_{2}\right)
$$

Condition (8) means that the overall cost of a NVI structure no longer depends on the price of the intermediate good $w_{Y_{1}}$. Moreover imposing this condition suppresses any misallocation of inputs due to market imperfection. Thus, any remaining economies of vertical integration are now purely technological. The technological economies of vertical integration, TVI, are measured by the ratio:

$$
\mathrm{TVI}=\frac{C^{v i}\left(Y_{2}, w_{1}, w_{2} \mid Z_{1}, Z_{2}\right)}{\widetilde{C}^{n v i}\left(Y_{2}, w_{1}, w_{2} \mid Z_{1}, Z_{2}\right)}
$$

If $T V I<1$ then the vertical structure is characterized by technological economies of vertical integration. If $T V I>1$, there are technological diseconomies of vertical integration. Finally, if $T V I=1$, there are neither technological economies nor diseconomies of vertical integration.

It should be noticed that the economies of vertical integration we have defined (both global and technological) are based on a comparison of the cost efficiency of the alternative vertical structures. One may argue that the normative implications derived from these measures should be treated with caution as a cost minimizing vertical structure may not be the one maximizing social welfare. In particular, if upstream market imperfections are diminished due to vertical integration, this may be a benefit of the integrated structure. However, society might be much worse off if upstream market power falls in the hands of a vertically integrated industry. Indeed, due to possible technical efficiencies, market power might be larger in the case of an integrated firm than in the case of two separate firms. But one specific characteristic of the water sector is that the final user market is usually regulated by a public authority. This is for instance the case in the US where State Public Service Commissions exercise their authority and influence to ensure that consumers receive safe, reliable and reasonably priced services from financially viable and technically competent utilities. If the final water market is highly regulated, what really matters in terms of social welfare is to minimize production costs. In such a case, the $G V I$ and TVI indexes will provide the public authority with an indication of the optimal vertical structure. 


\section{Vertical integration and costs for Wisconsin water utilities}

The Wisconsin case is quite typical of the North-American water industry. The water utilities in Wisconsin are on average small. In 2003, there were approximately five hundred water systems in Wisconsin, each delivering water to less than three thousand customers, on average. Most of the water services are municipally owned: in 2003, only 6 over the 512 utilities were privately owned. Wisconsin water utilities are regulated by the Public Service Commission of Wisconsin (PSC). The general principle of regulation for Wisconsin water utilities is a rate of return framework. However, in practice different regulatory schemes are implemented (regular rate of return, hybrid rate of return and interim price cap), see Aubert and Reynaud (2005) for further details.

\subsection{Vertically and non-vertically integrated water utilities in the Wisconsin}

Following the theoretical model, we consider a two-stage production model. The Production \& Treatment stage, P\&T, corresponds to resource extraction, transfer from the source of supply to the production facilities and treatment of raw water. The Transmission \& Distribution stage, $T \& D$, includes all the operations involved in the transmission of water to final customers through distribution mains and the customer services.

The PSC regulates three classes of water utilities defined by the number of final users. Due to data limitations, we were not able to keep the smallest utilities in our sample. We have a balanced panel of 211 services observed yearly from 1997 to 2000 in our sample. The vertically versus non-vertically utility groups are defined as follows:

- Vertically-integrated (VI) utilities. These utilities neither buy water from a wholesale supplier nor resell water to another service. They are 171 pure vertically integrated utilities.

- Non-vertically integrated (NVI) distribution utilities. 23 utilities report a positive quantity of water bought to another service but only 15 of these are classified as NVI distribution services. For the 15 services kept in our sample, the ratio of water bought to water produced is higher than $95 \%$ (11 services depend exclusively on a wholesale water supplier) whereas for the 8 dropped services, water brought from another utility is only a secondary source of water.

- Non-vertically integrated (NVI) production utilities. 23 services report a positive quantity of water sold to another water utility. In order to avoid any double counting, 6 services also buying water from another services have been dropped. For the 17 remaining (NVI 
production services), the ratio water volume sold to another service to total water volume sold varies from $1 \%$ to $35 \% .{ }^{10}$

From 1997 to 2000, 15.9 million of gallons of water have been sold on average each year by one water utility to another in the Wisconsin. This represents around $7.6 \%$ of the total water distributed. Both resale and final user water prices are regulated by the PSC. For instance, there exist some specific rules (the Purchased Water Adjustment Clause) that allow a supplier to revise its water price in case of an increase of the water wholesale price. The average water resale price for this period was 1.26 US\$ per thousand of gallons (Mgals), compared to the average water price for residential and industrial user, 2.73 and 1.53 US\$ per Mgals respectively.

As mentioned previously, one possible positive effect of vertical separation could be to induce more internal efficiency, see Grossman and Hart (1986). In the specific case of the water industry, vertical separation may induce more network efficiency at the downstream stage and so, more water savings. Due to market imperfections on the upstream market, the marginal price of purchased water can be higher than the first stage marginal cost of production. Hence, the downstream firm may face more incentives to reduce network water losses.

Table 1: Network efficiency and vertical integration

\begin{tabular}{lllllcccccc}
\hline & \multicolumn{4}{c}{ Network loss rate ${ }^{(a)}$} & \multicolumn{4}{c}{ Network loss index $^{(b)}$} \\
& Obs. & Mean & Min & Max & Std. Dev. & Mean & Min & Max & Std. Dev. \\
\hline Distribution Utilities & 60 & 0.123 & 0.000 & 0.453 & 0.118 & 0.251 & 0.000 & 0.854 & 0.225 \\
Integrated Utilities & 684 & 0.166 & 0.001 & 0.515 & 0.087 & 0.260 & 0.008 & 1.615 & 0.169 \\
\hline
\end{tabular}

${ }^{(a)}: 1$ - Volume sold/volume produced, in (\%).

${ }^{(b)}$ : (volume produced - Volume sold)/network length, in (Mgals/Feet).

In Table 1, we compare the network efficiency of water utilities according to the proportion of water purchased from another service. It is interesting to notice that the network loss rate is smaller for NVI distribution utilities than for VI utilities (about $12 \%$ on average versus more than $16 \%$ on average). This higher network efficiency of NVI distribution utilities may be attributed to a different network structure. In order to take into account this possible effect, a network loss index weighted by the network length has been computed. Results for this index are similar

\footnotetext{
${ }^{10}$ In the empirical application, we will control for the fact that these services are not pure NVI production utilities by incorporating the ratio, water volume sold to another service to total water volume sold, as a parameter of the cost function.
} 
(even if less strong) to those obtained with the network loss rate. Distribution utilities tend to have less network losses than integrated services.

\subsection{The data}

Most of the data used for the econometric application have been provided by the Public Service Commission (PSC) of Wisconsin and come from the annual report filled each year by each water utility. The annual reports provide expenses by production stage (source of supply, pumping, water treatment, transmission and distribution). However, as we do not observe capital expenses by production stage, we estimate a variable cost function for each stage. ${ }^{11}$

The P\&T or stage 1 output, $Y_{1}$, corresponds to the total water supply, that is the volume pumped from groundwater and/or withdrawn from surface water. $Y_{1}$ is measured in thousands of gallons (Mgal). The T\&D or stage 2 output, $Y_{2}$, is the volume in Mgal sold by the water utility to final customers.

We consider 6 inputs that may enter the production process at the P\&T stage and/or the T\&D stage: labor, energy, chemicals, operation supplies and expenses, maintenance and water purchased $Y_{1}$. The unit price of labor at stage $s, W_{L s}$ measured in US\$ per hour, has been derived from the Occupational Employment Statistics (OES) Survey published each year by the US Bureau of Labor Statistics, Department of Labor. ${ }^{12}$ The unit energy price, $w_{E}$, is measured in US\$ per thousands of kilowatts. The unit energy price has been computed by dividing the energy expenses by the quantity of energy used. The price of water is obtained by dividing the water purchase expenses by $Y_{1}$. The operation supplies and expenses and the maintenance inputs correspond to various heterogeneous inputs. As it is difficult to express these inputs in terms of physical quantity, $w_{O S E s}$ and $w_{M s}$ for $s=1,2$ have been obtained by dividing input expenses by the output of the corresponding stage, $Y_{s}$. Prices indexes are then defined in US\$ per unit of output, see Appendix A for more details. For the chemicals input as we do not observe any physical measure of the quantity used, we proceed in the same way and compute a price index as a unit cost per thousand of gallons treated. Some descriptive statistics may be found in Table 2 .

At the P\&T stage capital is represented by the actual capacity (in gallons per minute) of

\footnotetext{
${ }^{11}$ Working on the electric network industry, Kwoka (2002) concludes that there are three main sources for economies of vertical integration. The first and the largest cost saving from integration is the reduction in the operating and maintenance costs of power supply. The second source identified by the author is lower operation costs of both transmission and distribution for integrated systems. Last, reduction of overhead expenses can be expected in an integrated system. As all these costs are operating expenses, we believe that considering a variable cost function with capital as a quasi-fixed input should not bias our measure of EVI too much.

${ }^{12}$ See Appendix A for more details about the computation of $w_{L s}$.
} 
Table 2: Technological descriptive statistics

VI utilities: $N=171, T=4$

\begin{tabular}{|c|c|c|c|c|c|}
\hline Variable & Unit & Mean & Std. Dev. & Minimum & Maximum \\
\hline$Y_{2}$ & Mgals & 419,299 & 632,330 & 15,173 & $4,290,751$ \\
\hline$w_{L 1}$ & US\$/Hour & 15.77 & 1.83 & 10.98 & 21.07 \\
\hline$w_{O S E 1}$ & US $\$ / 1,000$ Mgals & 33.87 & 42.87 & 0.13 & 458.94 \\
\hline$w_{M 1}$ & US $\$ / 1,000$ Mgals & 72.56 & 98.48 & 0.06 & $1,345.53$ \\
\hline$w_{E 1}$ & US\$ / Mkwh & 64.39 & 22.09 & 0.09 & 334.79 \\
\hline$w_{C 1}$ & US $\$ / 1,000$ Mgals & 57.08 & 55.30 & 1.50 & 443.16 \\
\hline$w_{L 2}$ & US $\$ /$ Hour & 12.93 & 2.25 & 7.75 & 19.09 \\
\hline$w_{O S E 2}$ & US $\$ 1,000$ Mgals & 66.08 & 73.74 & 0.10 & 435.61 \\
\hline$w_{M 2}$ & US $\$ / 1,000$ Mgals & 202.31 & 141.89 & 0.99 & 868.75 \\
\hline Length & Feet & 252,186 & 275,575 & 17,435 & $1,731,558$ \\
\hline$C A P 1_{P}$ & Gals/minute & 4,176 & 5,760 & 1 & 33,201 \\
\hline$C A P 1_{W T}$ & Gals & 2.40 & 2.11 & 1 & 21.07 \\
\hline User & - & 3,137 & 3,775 & 57 & 22,919 \\
\hline$R t$ & $\%$ & 0.83 & 0.09 & 0.48 & 1.00 \\
\hline
\end{tabular}

NVI production utilities: $N=17, T=4$

\begin{tabular}{llllll}
\hline Variable & Unit & Mean & Std. Dev. & Minimum & \multirow{2}{*}{ Maximum } \\
\hline$Y_{1}$ & Mgals & $5,399,188$ & $11,047,260$ & 74,435 & $48,326,120$ \\
$w_{L 1}$ & US $\$$ Hour & 16.31 & 1.78 & 10.98 & 20.54 \\
$w_{O S E 1}$ & US\$ 1,000 Mgals & 18.83 & 24.34 & 0.06 & 109.05 \\
$w_{M 1}$ & US $\$ 1,000$ Mgals & 65.74 & 88.14 & 0.52 & 631.02 \\
$w_{E 1}$ & US $\$$ / Mkwh & 53.05 & 16.04 & 32.80 & 147.19 \\
$w_{C 1}$ & US $\$ 1,000$ Mgals & 65.09 & 75.56 & 5.45 & 269.34 \\
$C A P 1_{P}$ & Gals/minute & 79,029 & 204,338 & 650 & 876,000 \\
$C A P 1_{W T}$ & Gals & 10.79 & 18.86 & 0.30 & 79.00 \\
\hline
\end{tabular}

NVI distribution utilities: $N=15, T=4$

\begin{tabular}{llllll}
\hline Variable & Unit & Mean & Std. Dev. & Minimum & Maximum \\
\hline$Y_{2}$ & Mgals & 692,098 & 639,186 & 131,223 & $2,377,548$ \\
$w_{Y_{1}}$ & US\$/1,000 Mgals & 0.97 & 0.36 & 0.47 & 1.79 \\
$w_{L 2}$ & US\$/Hour & 11.24 & 1.08 & 9.88 & 14.99 \\
$w_{O S 2}$ & US\$/1,000 Mgals & 110.61 & 86.36 & 25.26 & 541.258 \\
$w_{M 2}$ & US\$/1,000 Mgals & 191.94 & 91.81 & 18.06 & 388.21 \\
Length & Feet & 361,906 & 287,858 & 87,677 & $1,098,054$ \\
User & - & 5,188 & 5,083 & 1,174 & 19,569 \\
$R t$ & $\%$ & 0.92 & 0.06 & 0.75 & 1.00 \\
\hline
\end{tabular}


the pumping and power equipment and by the storage capacity (in thousands of gallons) of reservoirs. These two variables are respectively denoted by $C A P 1_{P}$ and $C A P 1_{W T}$. The physical measure of the capital used for the T\&D stage is given by the length (in feet) of the distribution network, Length. The number of users is used as a technical variable, User. We also consider the network return as a technical variable. For a vertically-integrated utility, the difference $Y_{1}-Y_{2}$ mainly corresponds to the volume lost at the T\&D stage but also to losses at the P\&T stage and to the volume internally consumed by the water utility. Thus, the water network rate of

return $R t$ is equal to $\frac{Y_{2}}{Y_{1}}$. For a non-vertically integrated distribution utility, the network rate of return corresponds to the ratio between the volume injected into the network and the volume sold to final users. The difference between these two volumes is equal to the transmission and distribution losses.

The descriptive statistics presented in Tables 1 and 2 reveal that the network efficiency and the size of water utilities (level of water supplied, network length or capital) vary with the type of vertical organization. This may suggest that the water utilities are not randomly selected into VI or NVI groups. Comparing the cost functions for VI and NVI utilities may require to deal with this potential selectivity bias. We investigate this issue in the next section.

\subsection{The cost model}

One underlying assumption of neoclassical cost functions is that firms minimize their cost subject only to an output constraint. But some other constraints (type of regulation implemented, rigidity in some input use) may also affect the cost minimization behavior of a firm. The resulting cost function may differ from the neoclassical one. As discussed previously, although the general Wisconsin principle of regulation for utilities is a rate of return framework, more than two-thirds of the water utilities are regulated by an interim price cap scheme, see Aubert and Reynaud (2005). Hence, the cost minimization behavior of most water utilities in Wisconsin fits the neoclassical framework.

A functional form must be chosen in order to estimate the NVI and the VI cost functions. We use a translog approximation as it is convenient flexible functional form for computing substitution and network (density and scale) return measures, Christensen et al. (1973). The translog 
approximation of the cost function is, in vector form:

$$
\begin{aligned}
\ln (V C) & =\alpha_{0}+\sum_{i} \alpha_{i} \ln w_{i}+\alpha_{y} \ln Y \\
& +\frac{1}{2} \sum_{i} \sum_{i^{\prime}} \alpha_{i i^{\prime}} \ln w_{i} \ln w_{i^{\prime}}+\frac{1}{2} \alpha_{y y}(\ln Y)^{2}+\sum_{i} \alpha_{i y} \ln w_{i} \ln Y \\
& +\sum_{k} \alpha_{k} \ln Z_{k}
\end{aligned}
$$

where $V C$ is $N T \times 1$ and represents the variable cost. $N$ is the total number of individuals and $T$ the number of periods (panel data). $w$ represents the vector of input prices with $i$ indexing each input, $Y$ the output and $Z$ a vector of all other $(k)$ variables (capital and technical variables). Symmetry is imposed through the following restrictions: $\alpha_{i i^{\prime}}=\alpha_{i^{\prime} i}$. To ensure homogeneity of degree one in input prices, we divide the variable cost and the input prices by the price of a given input. ${ }^{13}$ The system of input demand equations is derived according to Shephard's lemma as:

$$
S_{i}=\alpha_{i}+\sum_{i^{\prime}} \alpha_{i i^{\prime}} \ln w_{i^{\prime}}+\alpha_{i y} \ln Y
$$

where $S_{i}$, a $N T \times 1$ vector, represents the cost share of input $i$. The system made of the cost function (15) and the cost share equations (16) less one ${ }^{14}$ is the cost model to be estimated.

\section{Assessing the economies of vertical integration}

\subsection{Estimation methods for the cost model}

The translog cost function along with its cost shares are estimated around the mean of observations (in logs). Hence, all right-hand side variables are normalized by their sample means. We add to each equation an independently and identically distributed error term. As is standard in panel data econometrics, the error term is decomposed in an unobservable individual specific effect and a classical disturbance term. Two different methods have been used to estimate the cost model.

We use the Generalized Method of Moments (GMM, see Hansen, 1982) to estimate the parameters of the cost model. This method possesses several interesting advantages. First, it requires neither a precise definition of the model nor a specification of its probability distribution

\footnotetext{
${ }^{13}$ This is equivalent to imposing a set of restrictions on cost function parameters : $\sum_{i} \alpha_{i}=1, \sum_{i} \alpha_{i i^{\prime}}=$ $\sum_{i^{\prime}} \alpha_{i i^{\prime}}=0, \sum_{i} \alpha_{i y}=0$.

${ }^{14} \mathrm{As}$ the sum of cost shares is equal to unity, one of them is dropped to avoid singularity of the variancecovariance matrix of errors.
} 
(as required by maximum likelihood methods, for instance). Moreover, as will be discussed, some variables in the right-hand side term of the system may be considered as endogenous. Hence, following Cornwell, Schmidt, and Wyhowski (1992), the GMM estimator with panel data is based on orthogonality conditions and Instrumental Variables (IV). Finally, the GMM method allows us to identify the parameters associated with variables that are not time variant (which is not possible using a Within method for instance).

For each equation of the cost model, we choose the instruments proposed by Hausman and Taylor (1981). ${ }^{15}$ Using the moment conditions approximated by their empirical counterpart leads to the GMM estimator of the system. The variance-covariance matrix is computed by first estimating the parameter vector with a unit variance-covariance matrix for error terms (IV method), and then minimizing the GMM criterion where the error terms are replaced by their first-step IV residual estimates. This produces heteroskedasticity-consistent parameter estimates. The system GMM estimator with panel data is: ${ }^{16}$

$$
\hat{\beta}_{S G M M}=\left(R^{\prime} A \hat{\Phi}^{-1} A^{\prime} R\right)^{-1} R^{\prime} A \hat{\Phi}^{-1} A^{\prime} Y
$$

where $Y$ is the $(M N T \times 1)$ vector of dependent variables, $R$ is the $M N T \times K$ matrix of regressors, $A$ is a $M N T \times L$ matrix of valid instruments, with $M$ denoting the number of equations in the cost system (cost and share equations), $N$ the number of utilities, $T$ the number of periods. Moreover, $\widehat{\Phi}$ is the variance-covariance matrix estimated from the IV residuals.

However, the GMM estimator possesses good properties only for large samples. As, we have a limited number of observations for NVI production and distribution utilities, we use another estimation method, based on the Seemingly Unrelated Regression approach (SUR, see Zellner, 1962). Considering the estimation of a set of SUR equations with panel data, we apply a fixed-effects method consisting in transforming all the variables of the system by the Within operator (variables with a tilde in the equation below). After a (first-step) OLS estimation on the transformed system, we replace error terms by Within-type residuals (see Baltagi, 1995, p.103), so that the Within-SUR estimator of the cost model is:

$$
\hat{\beta}_{W S U R}=\left[\tilde{R}^{\prime}\left(\hat{\Sigma}_{\varepsilon}^{-1} \otimes I_{H T}\right) \tilde{R}\right]^{-1} \tilde{R}^{\prime}\left(\hat{\Sigma}_{\varepsilon}^{-1} \otimes I_{H T}\right) \tilde{Y}
$$

\footnotetext{
${ }^{15}$ There exist even more efficient IV procedures, see Amemiya and MaCurdy (1986), and Breusch, Mizon, and Schmidt (1989). However, given the size of our sample, the number of overidentifying restrictions is already important and adding more instruments can lead to bias estimates. The choice of instruments is discussed in the following paragraphs.

${ }^{16}$ See Garcia and Reynaud (2004) for a more detailed description of the method.
} 
where $\hat{\Sigma}_{\varepsilon}$ is the variance-covariance matrix estimated from the Within residuals.

\subsection{Cost estimates results}

\subsubsection{Cost estimation and sample selection problem}

The cost functions for VI and NVI firms have been separately estimated. As there are some local factors that may explain the integration choice, any direct comparison of the two cost functions may suffer from a selection bias. In order to test whether this problem is significant or not, we explicitly model the vertical integration decision using a discrete choice model. ${ }^{17}$ For water service $i$, the choice at date $t$ between the two regimes (VI or NVI) is represented by the following sample selection equation:

$$
y_{i t}^{*}=\omega_{i t} \gamma+v_{i t},
$$

where $y_{i t}^{*}$ is a latent variable representing the cost differential between the two regimes and $\omega_{i t}$ a vector of exogenous variables. We consider a probit model, that is we assume that $v_{i t}$ is i.i.d. $\mathrm{N}(0,1)$. From the previous equation, service $i$ belongs to the VI regime if $y_{i t}^{*}>0$, that is:

$$
\operatorname{Pr}\left[i \in V I \mid \omega_{i t}\right]=\operatorname{Pr}\left[y_{i t}^{*}>0 \mid \omega_{i t}\right]=\operatorname{Pr}\left[v_{i t}>-\omega_{i t} \gamma\right]
$$

Notice that the selection equation depends on time, but in practice the service belongs to one of the two regimes for all time periods.

First, we consider the VI cost function (random effects model, see section 4.1). We denote by $y_{i t}$ the dependent variable (i.e. the variable cost) for the VI regime. The equation of primary interest is thus:

$$
y_{i t}=x_{i t} \beta+\alpha_{i}+\epsilon_{i t}
$$

where $\alpha_{i}$ is i.i.d. $\left(0, \sigma_{\alpha}\right), \epsilon_{i t}$ is i.i.d. $\left(0, \sigma_{\epsilon}\right)$ and $x_{i t}$ is a vector of variables influencing the cost. Using the previous equations, we have:

$$
E\left[y_{i t} \mid x_{i t}, i \in V I\right]=x_{i t} \beta+E\left[\alpha_{i}+\epsilon_{i t} \mid x_{i t}, v_{i t}>-\omega_{i t} \gamma\right]
$$

Since some regressors may be endogenous, the individual effects $\alpha_{i}$ can be correlated with some explanatory variables. Following Boumahdi and Thomas (1992), we suppose that the error terms

\footnotetext{
${ }^{17}$ Another approach would have been to follow a counterfactual method such as the one proposed by Lee (1978) or by Lee et al. (1980). Unfortunately, such an approach cannot be implemented in our case, mainly because the intermediate water price is not observed in the VI structure.
} 
of the selection equation may be correlated with the individual effects:

$$
E\left[\alpha_{i} \mid x_{i t}, v_{i t}>-\omega_{i t} \gamma\right]=\rho \lambda\left(\omega_{i t} \gamma\right)
$$

where $\rho$ is the unknown correlation coefficient between $\alpha_{i}$ and $\epsilon_{i t}$ and $\lambda$ denotes the inverse Mills ratio. The estimation procedure is the following one. First, following Wooldridge (2002), we estimate for each $t$ the equation $\operatorname{Pr}[i \in V I]=\phi\left(\omega_{i} \gamma_{t}\right)$ using a standard probit model and then we compute $\hat{\lambda}_{i t} \equiv \lambda\left(\omega_{i} \hat{\gamma}_{t}\right)$. Second, we estimate the cost equation including $\hat{\lambda}_{i t}$ as a regressor. Denoted by $\rho$ its associated parameter to be estimated, a simple test for selection bias consists in testing the null hypothesis $H_{0}: \rho=0$ using the t-statistic for $\rho$. As pointed out by Heckman (1979), this procedure allows us to consistently estimate all the parameters of the model.

Next, we consider the second regime that is the NVI structure (fixed effects model, see section 4.1). Since the individual effects disappear after the Within transformation, it follows that this estimator is affected neither by the endogeneity caused by some regressors nor by the endogeneity due to selectivity. ${ }^{18}$ Hence, we do not need to add a correction term related to the selectivity problem in the NVI regime.

As potential determinants of the VI/NVI choice, we include several technical variables related to network and production characteristics of the water services. These variables correspond to the determinants used for the estimation of the cost functions. ${ }^{19}$ In addition, some variables describing the local conditions of the county where the service is located are also used as potential factors explaining the choice of the vertical structure. ${ }^{20}$ The list of variables used in the probit selection equation and the estimation results are displayed in the appendix C. The McFadden's pseudo R-squared varies from 0.58 to 0.77 and the percentage of correctly predicted choices is greater than $95 \%$. First, the technical variables related to network and production characteristics seem to have only a limited impact of the probability of being VI. Only the input prices $\left(w_{L 2}\right.$ and $\left.w_{O S E 2}\right)$ have a significant impact and neither the length of network nor the number of users seem to be significant. On contrary, the local determinants have a significant impact on this choice.

\footnotetext{
${ }^{18}$ However, we have also considered the case where the correlation may exist between $\epsilon_{i t}$ and $v_{i t}$. In this case, the null hypothesis that $\rho$ is equal to zero is not rejected. Results are available upon request from the authors.

${ }^{19}$ We however impose some exclusion restrictions. First, we exclude from the selection equation some capital variables such as $C A P 1_{P}$ and $C A P 1_{W T}$ as well as some input prices such as $w_{O S E 1}, w_{M 1}, w_{E 1}, w_{C 1}$. As noted by Wooldridge (2002), the predicted inverse Mills ratio $\hat{\lambda}$ can be approximated by a linear function of the explanatory variables in the selection equation. If these variables are the same than those used in the regime equation, this can lead to a problem of collinearity resulting in large standard errors for the structural parameter estimates of the interest equation. Second, the network rate of return is also excluded as it is considered to be endogeneous.

${ }^{20}$ These variables include the population density, the average household income level or the share of one-unit detached housings. These data have been provided by the U.S. Census Bureau and by the U.S. Bureau of Economic Analysis and are defined at the county level.
} 
First, the income variable and the population density contribute negatively to the probability of being VI and a high proportion of one-unit detached housings or a high share of the service sector in the county GDP increase the probability to be VI. These results mean that, based on observables, the integration choice is not random. The next step is to include the inverse Mills ratio in the VI cost function, see column "Heckit" in Table D.1. The coefficient associated to the inverse Mills ratio is not statistically significant (a value of -0.0245 for a standard error of 0.0197). Hence we do not reject the null hypothesis of no selection bias. ${ }^{21}$ From this result, we conclude that there is no selection issue on unobservables.

\subsubsection{Vertically-integrated water utilities}

In order to use the GMM method, it is necessary to make some exogeneity assumptions for constructing the orthogonality conditions associated to the GMM criterion. There are several sources of potential endogeneity in our system of equations. First, the exogeneity of output levels is quite doubtful in practice. As shown in Table 1, the network loss rate differs according to the vertical structure of the water service. Garcia and Thomas (2001), working on a sample of French water utilities, have shown that there exists a trade-off between water network efficiency and costs of network repair. Injecting higher water volumes into the distribution network (and thus having higher losses) may be in some cases a cost effective alternative to network maintenance costs. For these reasons, the water output and the water network rate of return may be endogenous in our model. Second, as some input unit prices are computed as a function of the water output, they may be endogenous if the latter is. We will test the endogeneity of these variables using a Hansen test.

The Hausman-Taylor instruments have been used in the estimation process. The matrix of instruments is made of all time-varying regressors centered by the Within transformation and all time-varying regressors but the endogenous ones cited above and their associated crossproducts. ${ }^{22}$ The matrix of instruments also contains all time-invariant variables supposed to be exogenous. There are 50 parameters to be estimated with 88 instruments for the variable cost function of VI utilities. These 50 parameters are presented in Table D.1 in Appendix D. We have checked for the validity of the moment conditions with a Hansen test. The test statistic is equal to 60.25 with 70 degrees of freedom. ${ }^{23}$ With an associated p-value equal to 0.7906 , the

\footnotetext{
${ }^{21}$ In such a case, the unadjusted standard error for the Mills ratio presented in Table D.1 is valid, see Wooldridge (2002).

${ }^{22}$ Using Hansen tests, we do not reject the exogeneity of input prices.

${ }^{23}$ The entire cost system contains 113 parameters for 183 instruments.
} 
model specification and the choice of instruments are not rejected at the 5 percent level.

We have also reported in Table D.1 an estimation of the cost model using the iterated SURE method. The value of coefficients are similar.

Using Likelihood ratio tests, we have evaluated our cost specification. More specifically, we have tested the homotheticity of the production, the unitary substitution elasticity and the possibility of a Cobb-Douglas technology. All null hypotheses are rejected at the 5 percent level. Moreover, cost monotonicity and concavity in input prices are satisfied since the estimated cost shares are positive for a vast majority of observations ${ }^{24}$ and since the $\alpha_{i i^{\prime}}$ matrix (corresponding to the quadratic terms related to input prices) is negative semi-definite.

\subsubsection{Non-vertically integrated water utilities}

As the number of observations is limited to 68 for NVI production utilities and to 60 for NVI distribution utilities, the cost functions are estimated using a Within-SURE method detailed above. Notice that since the fixed term vanishes after the within transformation, the problem of correlation with regressors disappears. However, it is not possible to identify parameters of time-invariant regressors ${ }^{25}$ and the Within-SUR estimator is not efficient. In order to increase efficiency of the Within-SUR estimator, we use an iterative procedure $\grave{a}$ la Zellner. ${ }^{26}$ Results of these estimations are presented in Table D.2 and Table D.3. ${ }^{27}$

Last, we have carried out some specification tests for NVI production and distribution utilities. Only the homotheticity hypothesis (i.e. 4 restrictions) for the NVI distribution services has not been rejected at the 5 percent level. The value of the statistic is equal to 3.367 and the p-value of the test is 0.498 . We have imposed this constraint on the cost function, which reduces the number of parameters to be estimated. Finally, the properties of monotonicity and global concavity are verified ex-post.

\footnotetext{
${ }^{24}$ Only a very few estimated cost shares are negative due to the fact that some observed shares are very close to 0 .

${ }^{25}$ Only two regressors (i.e. the capital variables) in the NVI production cost model do not vary over time. The impact on EVI results is very limited since these variables are not significant in the VI cost function.

${ }^{26}$ The estimated variance covariance matrix obtained at the first GLS step is used to iteratively update the estimated parameter vector. This iterative procedure ends once the log-likehood has converged so that maximum likelihood estimates can be obtained.

${ }^{27}$ In order to check that firm's technological characteristics are not the same whether they are integrated or not, we have separately estimated the cost function for the production and the distribution stages using the VI utilities (684 observations). Then we have compared the estimated cost parameters with those obtained using the NVI production (68 observations) and distribution (60 observations) services. All these estimations are available from the authors upon request. The estimated coefficients appear to be significantly different both for the production and the distribution stages. This result tends to confirm that the technological characteristics of the water utilities differ according to the vertical structure (VI versus NVI). In such a case, estimating a single cost function on the whole dataset would clearly result in a misspecification of the econometric model.
} 


\subsection{Analysis of cost estimate}

From the cost function estimates, we have computed the average and marginal costs for the VI utilities and for the NVI utilities. We report these estimates in Table 3 for the average utility (at the sample mean of the variables).

Table 3: Estimates of marginal and average costs (in US\$ per Mgals) for the average utility

\begin{tabular}{llcc}
\hline & & Estimate & Std. Err. \\
\hline \multirow{2}{*}{ NVI Production utility } & MVC & 0.2275 & 0.0164 \\
& AVC & 0.2247 & 0.0299 \\
NVI Distribution utility & MVC & 1.2906 & 0.0778 \\
& AVC & 1.1800 & 0.0221 \\
VI utility & MVC & 0.7589 & 0.0594 \\
& AVC & 1.2021 & 0.0448 \\
\hline
\end{tabular}

Notes: MVC for marginal variable cost, AVC for average variable cost.

The results for marginal costs give a good idea of the cost differential between the two stages. In particular, for the average service the sum of marginal costs at each stage (in the NVI structure) is significantly greater than the overall marginal cost (in the VI structure). ${ }^{28}$ But these two figures are in fact not directly comparable since the NVI marginal cost include the water purchase expenses of the NVI distribution utility.

When we compare the MVC and AVC, the greater value of the AVC for the average VI utility seems to indicate the existence of economies of scale. The small difference between MVC and AVC for the NVI Utilities prompts us to be reserved on the nature of returns to scale. One possible explanation is that the size on the average VI utility (both measured in term of number of customers, water sold to final users, length of the network) is significantly smaller ${ }^{29}$ than the size of the average NVI utility. The VI utilities may not have exhausted all economies of scale. It is possible that imposing the average VI utility to produce higher level of water will not result in the presence of scale economies.

Following Caves et al. (1984), we now more formally consider the way the number of customers, the volume of production and the size of capital may affect the variable cost function.

\footnotetext{
${ }^{28}$ The null hypothesis of a sum of NVI marginal costs equal to the VI marginal cost is rejected at a $1 \%$ level of significance. The Student's t-statistic is equal to 4.43 .

${ }^{29}$ A simple unilateral test on the means allows for checking this statement.
} 
Considering both the number of customers and capital allows us to distinguish between returns to density (with respect to production) and returns to scale, see Garcia and Thomas (2001) for more details. ${ }^{30}$ All scale measures are computed for the average utility and are presented in Table 4 .

Table 4: Estimates of network returns for the average utility

\begin{tabular}{llcc}
\hline & & Estimate & Std. Err. \\
\hline NVI Production utility & $R T S_{S R}$ & 0.9875 & 0.0737 \\
NVI Distribution utility & $R T D_{S R}$ & 0.9143 & 0.0584 \\
& $R T S_{S R}$ & 1.1852 & 0.1404 \\
& $R T S_{L R}$ & 1.1913 & 0.1014 \\
VI utility & $R T D_{S R}$ & 1.5839 & 0.1155 \\
& $R T S_{S R}$ & 1.4029 & 0.1224 \\
& $R T S_{L R}$ & 1.1668 & 0.0879 \\
\hline
\end{tabular}

Notes: $R T D$ for returns to density, RTS for returns to scale. SR and LR means respectively short run and long run.

First, we find significant and important short run returns to density for the average VI utilities. This means that an increase in the demand per user will result in a decrease in the average cost. Second, there are significant (at a $1 \%$ confidence level) short run returns to scale for the average VI water utility. Moreover, at the sample mean, $R T S_{L R}$ is significantly different from 1 at a $10 \%$ level. The average VI utility is characterized by increasing short run and long run returns to scale. An increase in the service size (i.e. production, customers and network) will result in a decrease in average cost.

Concerning the average NVI production utility, we only report results for short run returns to scale since the SURE method does not allow us to identify coefficients related to capital variables. They are not significantly different from 1 at $5 \%$. The constant returns to scale for the average NVI production utility indicate that the production/generation stage could be considered as

\footnotetext{
${ }^{30}$ The short run returns to density $\left(R T D_{S R}\right)$ measure the cost savings that result from an increase in production, holding constant both the number of customers and the size of capital. $R T D_{S R}$ is equal to $1 / \varepsilon_{Y}$ where $\varepsilon_{Y}$ denotes the cost elasticity with respect to output. The short run returns to scale $\left(R T S_{S R}\right)$ measure the cost savings that result from an increase in production to satisfy the demand from new customers (here the demand per customer is constant) for a given level of capital. $R T S_{S R}$ is computed as $1 /\left(\varepsilon_{Y}+\varepsilon_{U}\right)$, where $\varepsilon_{C}$ is the cost elasticity with respect to the number of customers. The long run returns to scale $\left(R T S_{L R}\right)$ measure the proportional increase of water volume and number of users made possible by a proportional increase of all inputs (including capital). Denoting by $\varepsilon_{K}$ the cost elasticity with respect to capital $K$, the long run returns to scale are defined as $\left(1-\varepsilon_{K}\right) /\left(\varepsilon_{Y}+\varepsilon_{U}\right)$. Returns are increasing, constant or decreasing if the associated index $\left(R T D_{S R}, R T S_{S R}\right.$, $\left.R T S_{L R}\right)$ is greater than, equal to or less than 1, respectively. Notice that for NVI production utilities, returns to density and to scale cannot be differentiated because there is no distribution network and the only customer is the NVI distribution service.
} 
potentially competitive. However, the high standard error associated with $R T S$ for the average NVI production utility indicates that this result crucially depends on the size of the service. Indeed, the parameter related to the square of volume (in logarithm) in the cost function is significantly positive, see Table D.2. This means that the returns to scale decrease with the water production. The smallest NVI production utilities of our sample are in fact characterized by economies of scale.

Last, considering the short run returns to scale, our estimates suggest that the average NVI distribution utility is characterized by constant returns. In the other hand, the long run returns to scale for the average NVI distribution utilities are significantly greater than 1 (at a $10 \%$ level). On average the water utility has not exploited the economies of scale, so that the size of the network is not efficient.

\subsection{Results on vertical integration}

\subsubsection{Global economies of vertical integration}

In order to estimate $G V I$, we simulate the cost for different levels of final output and different prices for the intermediate good, both for a VI utility and for a NVI structure. More precisely, we proceed in the following way.

(1) We compute the estimated total cost for a VI utility assigned to sell to final users different water quantities $\left\{Y_{2_{1}}, \ldots, Y_{2_{K}}\right\}$ uniformly distributed over a relevant range of values.

(2) We compute the estimated cost for a NVI distribution utility, assigned to sell to final users the same quantities $\left\{Y_{2_{1}}, \ldots, Y_{2_{K}}\right\}$. For each quantity of final output $Y_{2_{k}}$, we consider $L$ possible prices of the intermediate good $\left\{w_{Y_{11}}, \ldots, w_{Y_{1 L}}\right\}$. This results in $K \times L$ estimates of the cost of the NVI distribution utility and $K \times L$ derived demands in water, $Y_{1}^{n v i}\left(Y_{2 k}, w_{Y_{1 l}}\right)$.

(3) We then compute the estimated cost for a NVI production utility assigned to produce the quantities $Y_{1}^{n v i}\left(Y_{2 k}, w_{Y_{1 l}}\right)$.

(4) We compute the total cost of production of the NVI structure, net of the water purchase cost for the intermediate good, for each $\left(Y_{2_{k}}, w_{Y_{1 l}}\right), \ldots, k=1, \ldots K$ and $l=1, \ldots L$.

(5) We compute the global economies of vertical integration $G V I$, defined by equation (7), for each $\left(Y_{2_{k}}, w_{Y_{1 l}}\right), \ldots, k=1, \ldots K$ and $l=1, \ldots L$. 


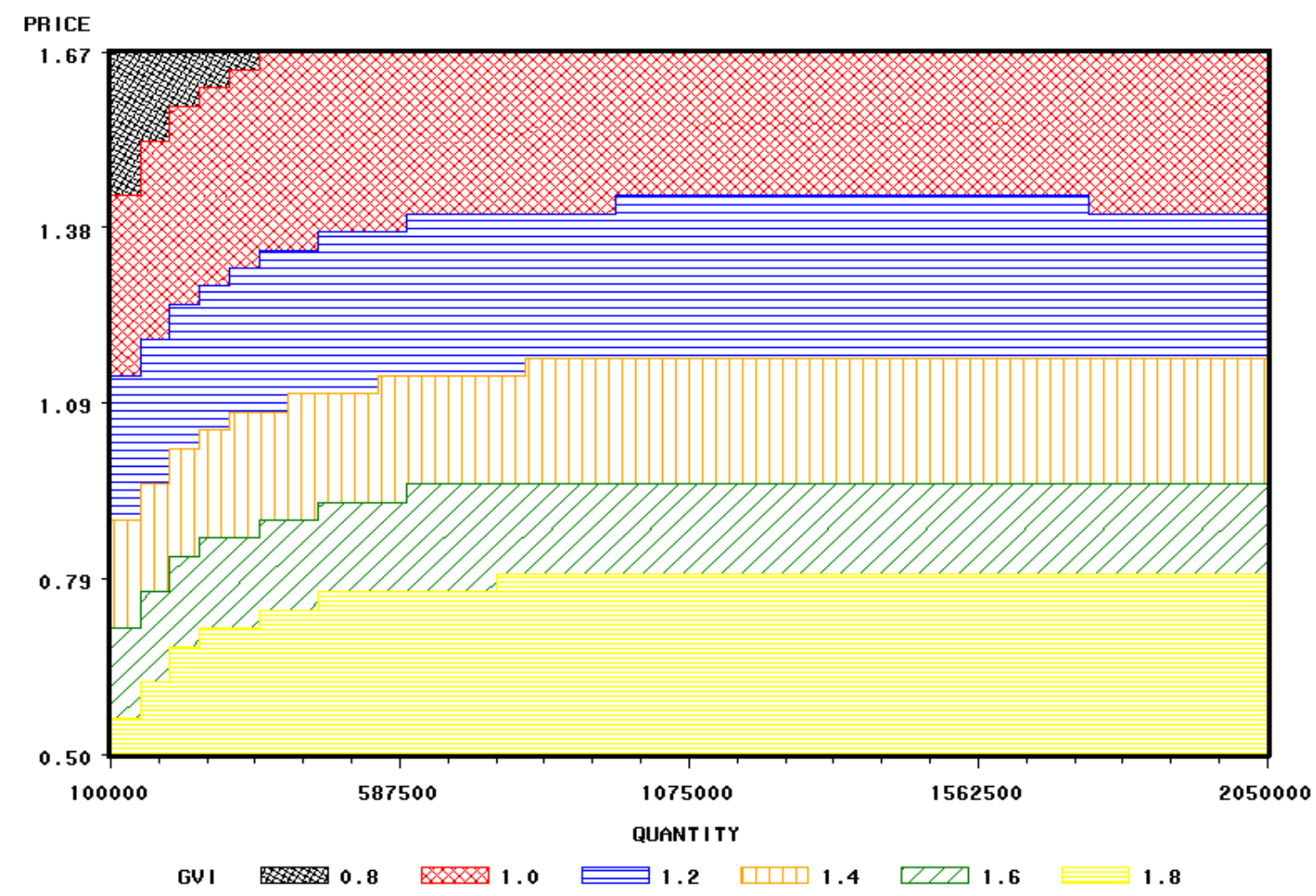

Figure 1: Global Economies of Vertical Integration

Notice that the capital variables are adjusted to each level of production. A statistical relationship between the level of production and the capital infrastructure (pumping and power equipment, storage capacity, network length) is first estimated for each class of utility. When computing the cost associated each production level, the capital variable is adjusted according to the estimated statistical relationship. We have considered input prices at the mean of our sample. As the cost of a non-vertically integrated structure depends on the price for intermediate water, $G V I$ are given for different levels of the final output but also for different prices of the intermediate good, see Figure 1.

First, in the $\left(w_{Y_{1}} \times Y_{2}\right)$ space we both observe zones characterized by global economies of vertical integration $(G V I \leq 1)$ and by diseconomies $(G V I>1)$. This means that there are zones where a VI structure can produce water at a lower cost than a NVI structure, and other where a NVI structure is more cost effective. We find that there are global economies of vertical integration for small services (i.e. for utilities characterized by a small volume of water sold to final users) and for a high intermediate water price (high intermediate prices create important distortions in terms of input allocation). For small utilities, integration involves important tech- 
nological and transactional economies. This suggests that undue fragmentation can lead to a misallocation of resources (fragmentation of responsibilities for planning, investment, operations and maintenance may lead to a loss of efficiency because decision-makers do not have an appropriate level of control over decisions and actions that affect their efficiency). It is also possible that the market power over the intermediate good does not favor small NVI distribution utilities. Hence, small utilities may find profitable to integrate vertically to reduce misallocations due to the upstream mark-up.

Second, for a given price of the intermediate water, the lower is the final output, the higher are global economies of vertical integration. One possible explanation is that, for small water utilities, the specialization of inputs across stages is quite limited because the production process is more simple. Hence, interdependences across stages are higher for small utilities than for large ones, which means that a VI structure is more cost effective in that case. For a given level of the final output, the higher is the intermediate water price, the higher are global economies of vertical integration. A high price of the intermediate water good means a high mark-up on the upstream market. This creates important distortions in terms of input allocation at the downstream stage. In such a case being integrated would result in important cost savings.

Third, it is interesting to see where the average Wisconsin VI and NVI distribution utilities are located in the $\left(w_{Y_{1}} \times Y_{2}\right)$ space. For the NVI distribution utilities, the average water price is 0.97 US $\$$ per Mgals and the average final volume sold is 692,098 Mgals. For these values the GVI index is equal to 1.45 . There are global diseconomies of vertical integration and a NVI structure is a cost effective solution. Next, we consider the average VI service. The water volume sold by the average VI utility to final users is equal to 419,299 Mgals. For such a level of water, we find global economies of vertical integration $(G V I<1)$ only for an intermediate water price greater than 1.49 US\$ per Mgals. It follows that for a lower water price, vertical separation would result, in such a case, in a cost saving.

Last, our findings are significantly different from what has been previously found by Kaserman and Mayo (1991), Kwoka (2002) and Nemoto and Goto (2004) working on the electric utility industry. They both found that vertical integration results in cost saving for almost all production levels, at the exception of the smallest ones. Kwoka (2002) reports for example that at the mean level for distribution and generation outputs, the efficiency gain from integration represents 42 percent of the cost. We also find global economies of vertical integration but only for small levels of the final output (or for prohibitive intermediate water price). One possible explanation is that the need for coordination between generation, transportation and distribution is much 
more important in the electric industry than in the water sector. It is for example well-known that a real-time management of power flows is required in order to guarantee energy balance in the network and to prevent failure of the system. In the same vein, as electricity flows across the network in accordance with the laws of physics, it cannot be controlled through a command and control system. This may impose high externality costs in case of non-vertically integrated systems. The need for such a coordination between the different stages is less stringent for a water network than for an electric system.

Our results also differ from those obtained for two other natural resource industries, namely the gas and the oil sectors. Oil and gas companies are usually active in several sectors of activity including exploration, production, transport, distribution. But, an important motivation for the vertical integration of oil and gas companies is to mitigate the impact of intermediate good price cycles and, hence to reduce profit volatility, Perruchet and Cueille (1991). Such an effect is not present in the water network industry as the water price does not strongly fluctuate. Before deriving the economic implications of these results, we still need to isolate the technological economies of vertical integration from the global ones.

\subsubsection{Technological economies of vertical integration}

We now evaluate the level of $T V I$. We proceed in the following way.

(1) We compute the estimated marginal cost of production for a non-vertically integrated producer utility for $K$ levels of the final output $Y_{1},\left\{Y_{1_{1}}, \ldots, Y_{1_{K}}\right\}$.

(2) Given that volumes $\left\{Y_{1_{1}}, \ldots, Y_{1_{K}}\right\}$ are sold by the non-vertically integrated producer to the non-vertically integrated retailer utility at the marginal cost, we compute the associated final output $\left\{Y_{2_{1}}, \ldots, Y_{2_{K}}\right\}$ and the associated costs.

(3) We compute the production cost of a vertically-integrated utility assigned to sell to final users the different quantities $\left\{Y_{2_{1}}, \ldots, Y_{2_{K}}\right\}$.

(4) We compute $T V I$ for $\left\{Y_{2_{1}}, \ldots, Y_{2_{K}}\right\}$ defined by equation (14).

In Figure 2, we have plotted TVI, defined by equation (14), as a function of the final output. Remember that $T V I \leq 1$ means that there are technological economies of vertical integration. First, there are technological economies of vertical integration only for small levels of final output (for a final output a little bit higher than 100,000 Mgals). This means that, if marginal cost pricing is implemented on the upstream market, a vertically integrated structure is a cost effective 


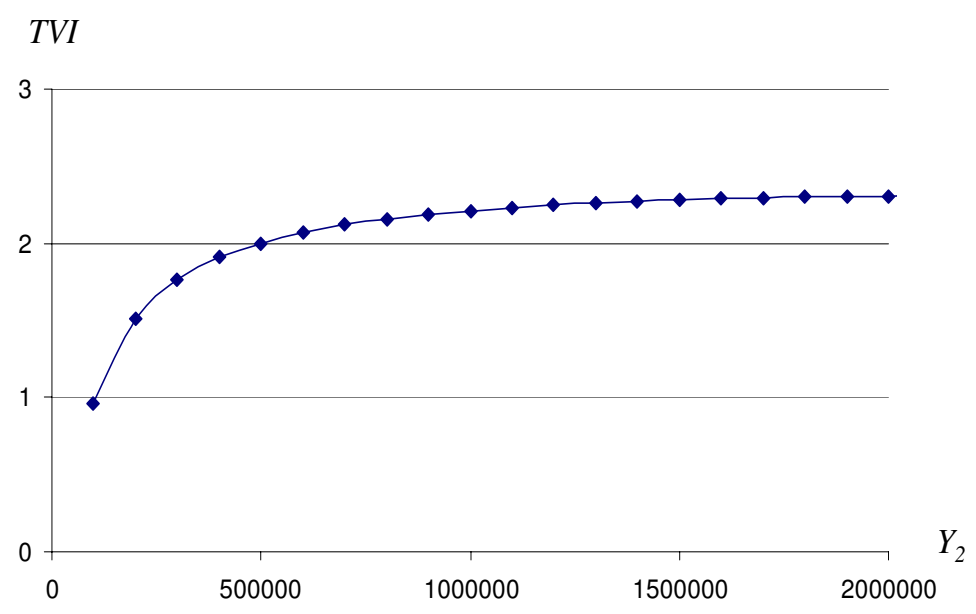

Figure 2: Technological Economies of Vertical Integration

solution only if the utility is small enough. The technological economies of vertical integration for small services can also be understood by considering the characteristics of their production and distribution costs. In case of a small size, the distribution service can capture the economies of scale at the production stage by integrating it. The aggregation of the average production and distribution cost functions allows production at a level with an overall average cost closer to its minimum.

From this Figure, the vertical organization of Wisconsin water utilities can be discussed. First, for 43 VI water utilities ( $25 \%$ of the sample), the volume of water sold to final users is smaller than 100,000 Mgals. As these services belong to a zone characterized by technological economies of vertical integration, their vertical organization is cost efficient. Notice however that, for the average VI Wisconsin water utility, the TVI index is equal to 1.94: if the regulator is able to enforce marginal cost pricing, vertical separation may result in important efficiency gains. Second, for all NVI distribution utilities, the volume of water sold to final user is greater than 100,000 Mgals. For those services, the vertical separation is a cost effective solution even if marginal cost pricing is enforced on the upstream market. To conclude, the technological economies of vertical integration help understanding why the average VI utility in the Wisconsin is smaller (both in terms of water delivery or customer number) than the NVI distribution utility.

These results are difficult to compare with the economies of vertical integration reported by Kwoka (2002) and by Kaserman and Mayo (1991) for the electric network industry because 
these papers do not distinguish the global economies of vertical integration from the technological ones. However given the high level of global economies reported in these papers, it is likely that applying our framework would result in finding technological economies of vertical integration for large electric utilities, an opposite conclusion to what we find for water utilities. We believe that specialization of inputs by production stage (or asset specialization) is much more important than coordination across stages for large water utilities than for large electric utilities. ${ }^{31}$ This may explain why large water utilities are characterized by important technical diseconomies of vertical integration whereas large electric utilities are more likely to present economies. The higher network efficiency of NVI distribution utilities (see Table 1) may be viewed as a result of the stage specialization.

\subsubsection{Discussion}

These results have some important policy implications in terms of water industry organization. But first, it is important to remember that a specific characteristic of the water sector is the regulation of the final market by a public authority. In particular the price of water delivered to final consumers is often, at least partially, under the control of the regulatory authority. This is clearly the case in the Wisconsin where all water utilities are regulated by the Public Service Commission. The general principle of regulation for Wisconsin water utilities is that 'All investors must receive a fair return on their investments [...] the PSC is required by law to provide an opportunity for the utility to earn a reasonable return to ensure adequate service'. By implementing this rate of return framework, the Public Service Commission of Wisconsin monitors the price paid by final users. ${ }^{32}$ It follows that, in terms of social welfare, what really matters is cost efficiency.

Based on efficiency considerations there is no clear answer to the debate about separation of production \& treatment and transportation \& distribution stages in the water industry. If the public authority cannot enforce marginal cost pricing on the upstream market, the cost efficient vertical structure is derived from the GVI index. Vertical integration should then be promoted only for the smallest size services. For instance, with a water price on the intermediate market

\footnotetext{
${ }^{31} \mathrm{~A}$ good example of coordination requirement between production and distribution in the electric industry is power pools. Power pools are agreements among independent utilities aiming at coordinating certain activities (joint scheduling of shutdowns for instance). To our knowledge, there are no similar agreements in the water sector. The main reason for connecting to water networks is to secure water sources. Technological economies of vertical integration from a better coordination of stages are likely small in the water industry.

${ }^{32}$ The PSC usually monitors water utility prices through a procedure called the simplified rate case which combines some aspects of a rate-of-return regulation with an upper bound for the water price increase. Moreover, a complete financial and a technical audit of the water utility can be implemented by the PSC staff.
} 
around 1.3 US\$ per Mgals, a vertical integration is a cost effective solution only for a final water volume lower than 150,000 Mgals per year. If the public authority can enforce marginal cost pricing on the upstream market then the optimal vertical structure is derived from the TVI index. Here, again, the vertical integration is a cost effective solution only for the smallest size services (for an annual volume of water sold to final users lower than 100,000 Mgals). It is clear that an important task of the regulator in such a case will be to enforce marginal cost pricing. It is likely that, given the limited number of production utilities, such a market will suffer from a lack of competition. The additional regulation cost should of course be taken into account to determine the optimal vertical structure of the water industry.

\section{Conclusion}

An important task of competition policy authorities is to isolate the natural monopoly activities of network industries from potentially competitive ones. The underlying objective is often to prevent the firms entrusted with such activities from extending their monopoly power on competitive segments. In network industries characterized by multi-stage production processes, achieving this objective requires analysis of the cost structure of vertically and non-vertically integrated firms. The question of vertical integration addressed in this paper is not a simple issue, as many factors need to be carefully analyzed. These factors include the technical, technological and economic constraints to separation. The potential benefits of vertical separation have to be carefully balanced against the loss of scope and scale economies, the costs of sector restructuring, and the possible loss of externality internalization. If these costs (in particular, economies of scope) are significant, there may be a case for the continuation of a verticallyintegrated monopoly. If not, vertical separation could be desirable. If parts of an industry must remain integrated, vertical conduct regulation or measures of partial vertical separation will be needed to establish conditions for effective competition.

In this context, identifying sources of economies of vertical integration is crucial. By estimating separately the cost function of vertically integrated and non-vertically integrated structures, we have proposed a framework that allows us to distinguish the technological economies of vertical integration from those resulting from inefficient input allocation due to upstream market imperfections. These issues related to the vertical integration of water utilities have been investigated by estimating the production and distribution cost function for some North American water utilities. By separately considering the production and the distribution stages, we have 
shown that disintegration of these two stages may lead to cost savings (with the exception of the smallest services). In addition, as the returns to scale at the production stage are shown to be constant, introducing competition could have some welfare improving effects.

Focusing only on global economies of vertical integration to assess the optimal structure of an industry can be misleading if those economies mainly result from cost distortions due to market imperfections. We have shown that there is no evidence of technological economies of vertical integration (at least for large utilities) between the production and distribution stages. This means that if marginal cost pricing can be enforced on the upstream market for the intermediate good, vertically disintegrated utilities should be promoted. This result for the water network industry appears to be different from what has been previously found for the electric industry, see Kaserman and Mayo (1991), Kwoka (2002) and Nemoto and Goto (2004) among others. We believe that for the water network industry, the specialization of inputs by production stage, or the asset specialization may generate more cost savings than the coordination across stages, a situation that may not hold for electric utilities. This may explain why most of the water utilities in our sample are characterized by important technological diseconomies of vertical integration. 


\section{References}

Amemiya, T., And T. MACuRdy (1986): "Instrumental-Variable Estimation of an ErrorComponents Model," Econometrica, 54(4), 869-880.

Aubert, C., And A. Reynaud (2005): "The Impact of Regulation on Efficiency: An Empirical Analysis of Wisconsin Water Utilities," Journal of Productivity Analysis, 23(3), 389-403.

Baltagi, B. H. (1995): Econometric Analysis of Panel Data. John Wiley \& Sons Ltd, Chichester.

Bisshop, A. (2001): "Multiplication des Opérateurs sur un Réseau d'Infrastructure Unique. Transposabilité des Évolutions dans les Télécommunications et l'Électricité en Europe sur les Réseaux d'Eau Potable," Synthèse technique. ENGREF, Montpellier.

Boumahdi, R., and A. Thomas (1992): "Estimation des Modèles à deux Régimes avec des Données de Panel," Annales d'Économie et de Statistique, 28, 125-142.

Breusch, T., G. Mizon, and P. Schmidt (1989): "Efficient Estimation Using Panel Data," Econometrica, 57(3), 695-700.

Caves, D. W., L. R. Christensen, and M. W. Tretheway (1980): "Flexible Cost Functions for Multiproduct Firms," Review of Economics and Statistics, 62(4), 477-481.

(1984): "Economies of Density versus Economies of Scale: Why Trunk and Local Service Airline Costs Differ Constraint," RAND Journal of Econmics, 15(4), 471-489.

Christensen, L. R., D. W. Jorgenson, and L. J. Lau (1973): "Transcendental Logarithmic Production Frontiers," Review of Economics and Statistics, 55, 28-45.

Cornwell, C., P. Schmidt, and D. Wyhowski (1992): "Simultaneous Equations and Panel Data," Journal of Econometrics, 51, 151-181.

European Commission (1999): "Liberalisation of Network Industries: Implications and Main Policy Issues," European Economy, Reports and Studies, No.4, Office for Official Publications of the EC, Luxembourg.

Garcia, S., and A. Reynaud (2004): "Estimating the Benefits of Efficient Water Pricing in France," Resource and Energy Economics, 26(1), 1-25.

Garcia, S., And A. Thomas (2001): "The Structure of Municipal Water Supply Costs: Application to a Panel French Local Communities," Journal of Productivity Analysis, 16(1), 5-31. 
Grossman, G. M., and O. Hart (1986): "The costs and Benefits of Ownership: A Theory of Vertical and Lateral Integration," Journal of Political Economy, 94(4), 691-719.

Hansen, L. (1982): "Large Sample Properties of Generalized Method of Moment Estimators," Econometrica, 50, 1029-1054.

Hausman, J., and W. Taylor (1981): "Panel Data and Unobservable Individual Effects," Econometrica, 49(6), 1377-1398.

Hayashi, P. M., J. Y.-J. Goo, and W. C. Chamberlain (1997): "Vertical Economies: The Case of US Electric Utility Industry, 1983-1987," Southern Economic Journal, 63(3), 710-725.

Heckman, J. J. (1979): "Sample Selection Bias as a spacification error," Econometrica, 47(1), $153-162$.

Jara-Díaz, S., F. J. Ramos-Real, and E. Martínez-Budría (2004): "Economies of Integration in the Spanish Electricity Industry Using a Multistage Cost Function," Energy Economics, 26(6), 995-1013.

Kaserman, D., And J. Mayo (1991): "The Measurement of Vertical Economies and the Efficient Structure of the Electric Utility Industry," Journal of Industrial Economics, 39(5), $483-502$.

Kwoka, J. E. (2002): "Vertical Economies in Electric Power: Evidence on Integration and its Alternative," International Journal of Industrial Organization, 20, 653-671.

LeE, B.-J. (1995): "Separability Test for the Electricity Supply Industry," Journal of Applied Econometrics, 10(1), 49-60.

LeE, L.-F. (1978): "Unionism and Wage Rates: A Simultaneous Equations Model with Qualitative and Limited Dependent Variables," International Economic Review, 19(2), 415-33.

Lee, L.-F., G. Maddala, and R. Trost (1980): “Asymptotic Covariance Matrices of TwoStage Probit and Two-Stage Tobit Methods for Simultaneous Equations Models with Selectivity," Econometrica, 48(2), 491-503.

Nemoto, J., And M. Goto (2004): "Technological Externalities and Economies of Vertical Integration in the Electric Utility Industry," International Journal of Industrial Organization, $22(1), 67-81$.

Perruchet, D., and J. Cueille (1991): "Vertical Integration and Risk Level in International Oil Companies," Oil \& Gas Science and Technology, 46(2), 277-288. 
Williamson, O. E. (1985): The Economic Institutions of Capitalism: Firms, Markets, Relational Contracting. The Free Press, New York.

Wooldridge, J. M. (2002): Econometric Analysis of Cross Section And Panel Data. The MIT Press, Cambridge, Massachusetts.

Zellner, A. (1962): "An Efficient Method of Estimating Seemingly Unrelated Regression and Test for Aggregation Bias," Journal of the American Statistical Association, 58, 348-368. 


\section{A Computation of input prices}

Labor The technical and financial annual reports give labor expenses at 5 steps of the production process: Source of supply (SS), Pumping (P), Treatment (T1), Transmission (T2), Customers account (CA) from 1997 to 2000. In order to estimate the two-stage cost function, we need to define the unit cost of labor for each water utility and at the P\&T and T\&D stages.

The unit cost of labor is derived from the Occupational Employment Statistics (OES) Survey published each year by the US Bureau of Labor Statistics, Department of Labor. This survey gives the mean hourly wage for the 11 Metropolitan Areas (MA) of the Wisconsin and for various occupations. We have matched each water utility with the corresponding Metropolitan Area. Then, we have matched each step (SS, P,T1, T2 and CA) with the OES corresponding occupation.

For each water utility, the $\mathrm{P} \& \mathrm{~T}$ unit cost of labor is then the sum of the unit labor costs for SS, P and T1 weighted by the expenses for these three categories. The T\&D labor cost corresponds to the sum of the unit labor costs for $\mathrm{T} 2$ and $\mathrm{CA}$ weighted by the expenses for these two categories. Both labor prices $w_{L s} s=1,2$ are in $U S \$ /$ hours.

Energy and Purchased water The price of energy $w_{E}$ is defined as the expenses for fuel or power purchased divided by the quantity of energy used in thousands of kilowatts per hour $(M k W h)$. The unit price of energy is thus defined in US\$ per $M k W h$. The price of purchased water $w_{Y_{1}}$ is defined as the ratio of purchased water expenses to the quantity of water purchased in thousands of gallons (Mgals). The unit price for the water input is in US\$ per Mgals.

Operation supplies and expenses, Maintenance and Chemical The main difficulty is that expenses associated to these inputs are very heterogeneous. In order to construct a price index associated to each input, $w_{O E S s}$ and $w_{M s}$ for $s=1$, 2 , we have divided input expenses by the output of the stage considered, $Y_{s}$ in millions of gallons (MMgals). Price indexes are defined in US\$ per unit of output. The implicit assumption is that the unobserved quantity of input increases proportionally with the level of output. For the chemical input we do not observe any physical measure of the quantity used by the water utility. A price index is construct by dividing expenses for chemical by $Y_{1}$ in MMgals. The price of chemical is defined in US\$ per MMgals. 


\section{B Input shares and cost descriptive statistics}

Table B.1: Cost descriptive statistics for VI utilities, 684 observations

\begin{tabular}{lllll}
\hline Variable & Mean & Min. & Max. & Std. Dev. \\
\hline$V_{C}$ & 444,373 & 31,191 & $3,740,468$ & 512,805 \\
$S_{L 1}$ & 0.1025 & 0.000 & 0.344 & 0.0758 \\
$S_{O S E 1}$ & 0.0248 & 0.000 & 0.300 & 0.0327 \\
$S_{M 1}$ & 0.0575 & 0.000 & 0.519 & 0.0587 \\
$S_{E 1}$ & 0.1115 & 0.000 & 0.583 & 0.0575 \\
$S_{C 1}$ & 0.0440 & 0.000 & 0.256 & 0.0409 \\
$S_{L 2}$ & 0.3142 & 0.027 & 0.660 & 0.1123 \\
$S_{O S E 2}$ & 0.1792 & 0.030 & 0.525 & 0.0746 \\
$S_{M 2}$ & 0.1663 & 0.002 & 0.594 & 0.0863 \\
\hline
\end{tabular}

Table B.2: Cost descriptive statistics for NVI production utilities, 68 observations

\begin{tabular}{lllll}
\hline Variable & Mean & Min. & Max. & Std. Dev. \\
\hline$V C$ & $1,409,931$ & 27,144 & $11,984,756$ & $2,683,740$ \\
$S_{L 1}$ & 0.3203 & 0.110 & 0.578 & 0.1388 \\
$S_{O S E 1}$ & 0.0538 & 0.001 & 0.206 & 0.0485 \\
$S_{M 1}$ & 0.1710 & 0.003 & 0.468 & 0.0909 \\
$S_{E 1}$ & 0.3090 & 0.072 & 0.629 & 0.1342 \\
$S_{C 1}$ & 0.1459 & 0.000 & 0.395 & 0.1078 \\
\hline
\end{tabular}


Table B.3: Cost descriptive statistics for NVI distribution utilities, 60 observations

\begin{tabular}{lllll}
\hline Variable & Mean & Min. & Max. & Std. Dev. \\
\hline$V C$ & $1,079,309$ & 347,704 & $3,595,949$ & 920,102 \\
$S_{Y_{1}}$ & 0.6194 & 0.397 & 0.798 & 0.0908 \\
$S_{L 2}$ & 0.1435 & 0.060 & 0.348 & 0.0584 \\
$S_{O S E 2}$ & 0.1024 & 0.032 & 0.280 & 0.0504 \\
$S_{M 2}$ & 0.1347 & 0.008 & 0.301 & 0.0644 \\
\hline
\end{tabular}




\section{Probit selection equation}

Table C.1: Descriptive statistics for the variables used in the Probit selection equation

\begin{tabular}{llllll}
\hline \multirow{2}{*}{ Variable } & & \multicolumn{2}{c}{ VI structure } & \multicolumn{2}{c}{ NVI structure } \\
& Definition & Mean & Std. Dev. & Mean & Std. Dev. \\
\hline$Y_{2}$ & Volume sold to final users (in Mgals) & 419,299 & 632,330 & 692,098 & 639,186 \\
$w_{L 2}$ & Labor input price (in US\$ /Hour) & 12.93 & 2.25 & 11.24 & 1.08 \\
$w_{O S E 2}$ & Input price for Operation Supplies & 66.08 & 73.74 & 110.61 & 86.36 \\
& and Expenses (in US\$/1,000Mgals) & & & & \\
$w_{M 2}$ & Maintenance input price (in US $\$ / 1,000$ Mgals) & 202.31 & 141.89 & 191.94 & 91.81 \\
Length & Total length of the water network (in feet) & 252,186 & 275,575 & 361,906 & 287,858 \\
User & Number of users & 3,137 & 3,775 & 5,188 & 5,083 \\
Income & Median household income (in US\$) & 34,144 & 6,059 & 35,635 & 1,879 \\
Density & Number of inhabitants per square miles & 229 & 595 & 2,317 & 1,785 \\
Housing & Share of one-unit detached housings & 0.71 & 0.08 & 0.55 & 0.12 \\
Earning & Share of the service sector into the GDP & 0.17 & 0.05 & 0.23 & 0.05 \\
\hline
\end{tabular}

Table C.2: Estimation results of the Probit selection equation

\begin{tabular}{|c|c|c|c|c|c|c|c|c|}
\hline \multirow[b]{2}{*}{ Variable } & \multicolumn{2}{|c|}{$\mathrm{t}=1$} & \multicolumn{2}{|c|}{$t=2$} & \multicolumn{2}{|c|}{$\mathrm{t}=3$} & \multicolumn{2}{|c|}{$\mathrm{t}=4$} \\
\hline & Coef. & Std. Err. & Coef. & Std. Err. & Coef. & Std. Err. & Coef. & Std. Err. \\
\hline Constant & -5.9565 & 5.8394 & $-20.2503^{* *}$ & 9.1727 & $-39.8032 * *$ & 19.2414 & $-17.4738^{* *}$ & 8.4291 \\
\hline$Y_{2}$ & -0.0002 & 0.0010 & 0.0001 & 0.0012 & -0.0018 & 0.0021 & -0.0006 & 0.0014 \\
\hline$w_{L 2}$ & $0.6606^{* *}$ & 0.2908 & $1.0601^{* * *}$ & 0.3698 & $1.8011^{* *}$ & 0.7134 & $0.7944^{* * *}$ & 0.2121 \\
\hline$w_{O S E 2}$ & $-0.0079 * * *$ & 0.0029 & $-0.0091 * * *$ & 0.0035 & $-0.0172 * *$ & 0.0070 & $-0.0098^{* *}$ & 0.0042 \\
\hline$w_{M 2}$ & 0.0017 & 0.0023 & 0.0042 & 0.0028 & 0.0035 & 0.0036 & 0.0013 & 0.0024 \\
\hline Length & 0.0012 & 0.0026 & 0.0018 & 0.0036 & 0.0013 & 0.0053 & -0.0025 & 0.0032 \\
\hline User & -0.0472 & 0.1610 & -0.1082 & 0.2618 & 0.0278 & 0.4523 & 0.2586 & 0.2787 \\
\hline Income & $-0.1872^{*}$ & 0.0985 & $-0.3073^{* *}$ & 0.1244 & $-0.6558^{* *}$ & 0.2743 & $-0.3249 * * *$ & 0.1130 \\
\hline Density & $-0.0013 * * *$ & 0.0005 & $-0.0008^{*}$ & 0.0004 & $-0.0015^{* *}$ & 0.0007 & $-0.0013 * *$ & 0.0005 \\
\hline Housing & 5.8809 & 6.2029 & $21.5017^{* *}$ & 20.0137 & $42.6840^{* *}$ & 20.0137 & $19.5162^{* *}$ & 8.9979 \\
\hline Earning & 25.6467 & 17.7368 & $40.7946^{*}$ & 21.0076 & $103.2003^{* *}$ & 50.1948 & $47.8018^{* *}$ & 23.4963 \\
\hline Pseudo $\mathrm{R}^{2}$ & \multicolumn{2}{|c|}{0.58} & \multicolumn{2}{|c|}{0.64} & \multicolumn{2}{|c|}{0.77} & \multicolumn{2}{|c|}{0.71} \\
\hline
\end{tabular}

Notes: $Y=0$ corresponds to the NVI structure $(N=15), Y=1$ corresponds to VI structure $(N=171)$.

***: significant at 1 percent, ${ }^{* *}$ : significant at 5 percent, $*$ : significant at 10 percent. 
D Cost functions estimates 
Table D.1: Cost function for VI utilities

\begin{tabular}{|c|c|c|c|c|c|c|}
\hline \multirow[b]{2}{*}{ Variable (in $\log$ ) } & \multicolumn{2}{|c|}{ HECKIT } & \multicolumn{2}{|c|}{ GMM } & \multicolumn{2}{|c|}{ Iterated SURE } \\
\hline & Coef. & Std. Err. & Coef. & Std. Err. & Coef. & Std. Err. \\
\hline Constant & $9.7231^{* * *}$ & 0.0372 & $9.7213^{* * *}$ & 0.0373 & - & - \\
\hline$Y_{2}$ & $0.6296^{* * *}$ & 0.0458 & $0.6313^{* * *}$ & 0.0461 & $0.6840^{* * *}$ & 0.0377 \\
\hline$w_{O S E 1}$ & $0.0248^{* * *}$ & 0.0032 & $0.0248^{* * *}$ & 0.0032 & $0.0305^{* * *}$ & 0.0042 \\
\hline$w_{M 1}$ & $0.0603^{* * *}$ & 0.0037 & $0.0603^{* * *}$ & 0.0037 & $0.0681^{* * *}$ & 0.0030 \\
\hline$w_{E 1}$ & $0.0627^{* * *}$ & 0.0165 & $0.0632^{* * *}$ & 0.0165 & $0.0671^{* * *}$ & 0.0066 \\
\hline$w_{C 1}$ & $0.0694^{* * *}$ & 0.0150 & $0.0707^{* * *}$ & 0.0151 & $0.0565^{* * *}$ & 0.0077 \\
\hline$w_{L 2}$ & $0.3117^{* * *}$ & 0.0127 & $0.3118^{* * *}$ & 0.0127 & $0.3540^{* * *}$ & 0.0260 \\
\hline$w_{O S E 2}$ & $0.1793^{* * *}$ & 0.0072 & $0.1794^{* * *}$ & 0.0071 & $0.1681^{* * *}$ & 0.0099 \\
\hline$w_{M 2}$ & $0.1684^{* * *}$ & 0.0052 & $0.1684^{* * *}$ & 0.0052 & $0.1818^{* * *}$ & 0.0049 \\
\hline$Y_{2} \cdot Y_{2}$ & 0.0187 & 0.0480 & 0.0145 & 0.0484 & $0.0887^{* * *}$ & 0.0342 \\
\hline$w_{O S E 1} \cdot w_{O S E 1}$ & $0.0144^{* * *}$ & 0.0017 & $0.0145^{* * *}$ & 0.0017 & $0.0138^{* * *}$ & 0.0008 \\
\hline$w_{M 1} \cdot w_{M 1}$ & $0.0357^{* * *}$ & 0.0025 & $0.0358^{* * *}$ & 0.0025 & $0.0358^{* * *}$ & 0.0011 \\
\hline$w_{E 1} \cdot w_{E 1}$ & $0.0262^{* * *}$ & 0.0039 & $0.0263^{* * *}$ & 0.0039 & $0.0296^{* * *}$ & 0.0014 \\
\hline$w_{C 1} \cdot w_{C 1}$ & $0.0297^{* * *}$ & 0.0033 & $0.0297^{* * *}$ & 0.0033 & $0.0298^{* * *}$ & 0.0012 \\
\hline$w_{L 2} \cdot w_{L 2}$ & $0.0656^{* *}$ & 0.0333 & $0.0656^{* *}$ & 0.0332 & $0.0804^{* *}$ & 0.0122 \\
\hline$w_{O S E 2} \cdot w_{O S E 2}$ & $0.1012^{* * *}$ & 0.0087 & $0.1013^{* * *}$ & 0.0086 & $0.1023^{* * *}$ & 0.0030 \\
\hline$w_{M 2} \cdot w_{M 2}$ & $0.0896^{* * *}$ & 0.0053 & $0.0897^{* * *}$ & 0.0053 & $0.1009^{* * *}$ & 0.0020 \\
\hline$w_{O S E 1} \cdot w_{M 1}$ & -0.0001 & 0.0012 & 0.0000 & 0.0012 & 0.0003 & 0.0006 \\
\hline$w_{O S E 1} \cdot w_{E 1}$ & -0.0002 & 0.0018 & -0.0002 & 0.0018 & -0.0019 & 0.0008 \\
\hline$w_{O S E 1} \cdot w_{C 1}$ & 0.0000 & 0.0015 & 0.0000 & 0.0015 & -0.0007 & 0.0006 \\
\hline$w_{O S E 1} \cdot w_{L 2}$ & -0.0042 & 0.0044 & -0.0042 & 0.0044 & -0.0003 & 0.0020 \\
\hline$w_{O S E 1} \cdot w_{O S E 2}$ & $-0.0045^{*}$ & 0.0026 & $-0.0045^{*}$ & 0.0026 & $-0.0056^{* * *}$ & 0.0011 \\
\hline$w_{O S E 1} \cdot w_{M 2}$ & -0.0029 & 0.0024 & -0.0029 & 0.0024 & $-0.0028^{* * *}$ & 0.0009 \\
\hline$w_{M 1} \cdot w_{E 1}$ & $-0.0045^{* * *}$ & 0.0016 & $-0.0045^{* * *}$ & 0.0016 & $-0.0040 * * *$ & 0.0006 \\
\hline$w_{M 1} \cdot w_{C 1}$ & -0.0017 & 0.0012 & -0.0017 & 0.0012 & $-0.0023^{* * *}$ & 0.0004 \\
\hline$w_{M 1} \cdot w_{L 2}$ & $-0.0142^{* * *}$ & 0.0037 & $-0.0142^{* * *}$ & 0.0037 & $-0.0137^{* * *}$ & 0.0015 \\
\hline$w_{M 1} \cdot w_{O S E 2}$ & $-0.0062^{* *}$ & 0.0024 & $-0.0062^{* * *}$ & 0.0024 & $-0.0063^{* * *}$ & 0.0009 \\
\hline$w_{M 1} \cdot w_{M 2}$ & $-0.0043^{*}$ & 0.0024 & $-0.0044^{*}$ & 0.0024 & $-0.0044^{* * *}$ & 0.0011 \\
\hline$w_{E 1} \cdot w_{C 1}$ & -0.0018 & 0.0026 & -0.0018 & 0.0026 & 0.0007 & 0.0008 \\
\hline$w_{E 1} \cdot w_{L 2}$ & 0.0041 & 0.0080 & 0.0040 & 0.0079 & $-0.0117^{* * *}$ & 0.0015 \\
\hline$w_{E 1} \cdot w_{O S E 2}$ & $-0.0120^{* * *}$ & 0.0041 & $-0.0119 * * *$ & 0.0041 & $0.0004^{* *}$ & 0.0019 \\
\hline$w_{E 1} \cdot w_{M 2}$ & -0.0027 & 0.0059 & -0.0026 & 0.0058 & $-0.0118^{* * *}$ & 0.0010 \\
\hline$w_{C 1} \cdot w_{L 2}$ & -0.0072 & 0.0071 & -0.0074 & 0.0071 & $-0.0118^{* * *}$ & 0.0028 \\
\hline$w_{C 1} \cdot w_{O S E 2}$ & -0.0057 & 0.0035 & -0.0058 & 0.0035 & $-0.0054^{* * *}$ & 0.0012 \\
\hline$w_{C 1} \cdot w_{M 2}$ & $-0.0139 * * *$ & 0.0038 & $-0.0139 * * *$ & 0.0037 & $-0.0061^{* * *}$ & 0.0007 \\
\hline$w_{L 2} \cdot w_{O S E 2}$ & $-0.0435^{* * *}$ & 0.0111 & $-0.0434^{* * *}$ & 0.0110 & $-0.0467^{* * *}$ & 0.0045 \\
\hline$w_{L 2} \cdot w_{M 2}$ & $-0.0268^{* *}$ & 0.0116 & $-0.0268^{* *}$ & 0.0116 & $-0.0404^{* * *}$ & 0.0025 \\
\hline$w_{O S E 2} \cdot w_{M 2}$ & $-0.0272^{* * *}$ & 0.0059 & $-0.0273^{* * *}$ & 0.0058 & $-0.0227^{* * *}$ & 0.0014 \\
\hline$Y_{2} \cdot w_{O S E 1}$ & 0.0018 & 0.0048 & 0.0018 & 0.0049 & 0.0012 & 0.0033 \\
\hline$Y_{2} \cdot w_{M 1}$ & $0.0097^{*}$ & 0.0050 & $0.0092^{*}$ & 0.0050 & $0.0070^{* * *}$ & 0.0025 \\
\hline$Y_{2} \cdot w_{E 1}$ & $0.0199^{*}$ & 0.0113 & $0.0208^{*}$ & 0.0112 & $0.0209 * * *$ & 0.0048 \\
\hline$Y_{2} \cdot w_{C 1}$ & -0.0011 & 0.0081 & -0.0007 & 0.0081 & 0.0041 & 0.0041 \\
\hline$Y_{2} \cdot w_{L 2}$ & $-0.0707^{* * *}$ & 0.0201 & $-0.0706^{* * *}$ & 0.0201 & $-0.0452^{* * *}$ & 0.0142 \\
\hline$Y_{2} \cdot w_{O S E 2}$ & $0.0313^{* * *}$ & 0.0110 & $0.0308^{* * *}$ & 0.0109 & $0.0236^{* * *}$ & 0.0070 \\
\hline$Y_{2} \cdot w_{M 2}$ & $0.0127^{*}$ & 0.0072 & $0.0134^{*}$ & 0.0072 & $0.0167^{* * *}$ & 0.0038 \\
\hline Length & $0.1729 * *$ & 0.0870 & $0.1683^{*}$ & 0.0878 & $0.0332^{*}$ & 0.0512 \\
\hline$C A P 1_{P}$ & 0.0101 & 0.0285 & 0.0105 & 0.0287 & - & - \\
\hline$C A P 1_{W T}$ & 0.1632 & 0.1072 & 0.1697 & 0.1081 & - & - \\
\hline User & 0.0816 & 0.0596 & 0.0815 & 0.0602 & -0.0140 & 0.0262 \\
\hline$R t$ & $-0.4185^{* * *}$ & 0.0967 & $-0.4105^{* * *}$ & 0.0970 & $-0.5289 * * *$ & 0.0365 \\
\hline Mills & -0.0245 & 0.0197 & - & - & - & - \\
\hline Adjusted $\Omega$ & & & & & 0.8 & 24 \\
\hline
\end{tabular}

Notes: $\mathrm{N}=171, \mathrm{~T}=4$. The Heckit standard errors are unadjusted.

${ }^{* * *}$ : significant at 1 percent, ${ }^{* *}$ : significant at 5 percent, ${ }^{*}$ : significant at 10 percent. 
Table D.2: Cost function for NVI production utilities (Within-SURE)

\begin{tabular}{|c|c|c|c|c|}
\hline \multirow[b]{2}{*}{ Variable (in log) } & \multicolumn{2}{|c|}{ SURE } & \multicolumn{2}{|c|}{ Iterated SURE } \\
\hline & Coef. & Std. Err. & Coef. & Std. Err. \\
\hline$Y_{1}$ & $0.9700 * * *$ & 0.0895 & $1.0127 * * *$ & 0.0756 \\
\hline$w_{L 1}$ & -0.0375 & 0.0554 & -0.0213 & 0.0527 \\
\hline$w_{O S E 1}$ & $0.0525 * * *$ & 0.0117 & $0.0512^{* * *}$ & 0.0127 \\
\hline$w_{M 1}$ & $0.2605 * * *$ & 0.0139 & $0.2629 * * *$ & 0.0150 \\
\hline$w_{E 1}$ & $0.3817^{* * *}$ & 0.0471 & $0.3426^{* * *}$ & 0.0456 \\
\hline$w_{C 1}$ & $0.3428^{* * *}$ & 0.0377 & $0.3646^{* * *}$ & 0.0375 \\
\hline$Y_{1} \cdot Y_{1}$ & $0.2661^{* * *}$ & 0.0670 & $0.2573^{* * *}$ & 0.0578 \\
\hline$w_{L 1} \cdot w_{L 1}$ & $0.0637^{* * *}$ & 0.0206 & $0.0668^{* * *}$ & 0.0205 \\
\hline$w_{O S E 1} \cdot w_{O S E 1}$ & $0.0211^{* * *}$ & 0.0031 & $0.0193^{* * *}$ & 0.0030 \\
\hline$w_{M 1} \cdot w_{M 1}$ & $0.1013^{* * *}$ & 0.0060 & $0.1166^{* * *}$ & 0.0051 \\
\hline$w_{E 1} \cdot w_{E 1}$ & $0.0520 * * *$ & 0.0143 & $0.0518^{* * *}$ & 0.0136 \\
\hline$w_{C 1} \cdot w_{C 1}$ & $0.0801^{* * *}$ & 0.0133 & $0.0844^{* * *}$ & 0.0121 \\
\hline$Y_{1} \cdot w_{L 1}$ & $-0.1074^{* * *}$ & 0.0254 & $-0.0776^{* * *}$ & 0.0231 \\
\hline$Y_{1} \cdot w_{O S E 1}$ & 0.0085 & 0.0091 & 0.0071 & 0.0081 \\
\hline$Y_{1} \cdot w_{M 1}$ & $0.0141^{*}$ & 0.0075 & $0.0278^{* * *}$ & 0.0066 \\
\hline$Y_{1} \cdot w_{E 1}$ & $0.0697^{* * *}$ & 0.0193 & $0.0576 * * *$ & 0.0172 \\
\hline$Y_{1} \cdot w_{C 1}$ & 0.0150 & 0.0197 & -0.0146 & 0.0174 \\
\hline$w_{L 1} \cdot w_{O S E 1}$ & 0.0026 & 0.0048 & 0.0055 & 0.0047 \\
\hline$w_{L 1} \cdot w_{M 1}$ & $-0.0216^{* * *}$ & 0.0056 & $-0.0306^{* * *}$ & 0.0053 \\
\hline$w_{L 1} \cdot w_{E 1}$ & 0.0164 & 0.0143 & 0.0155 & 0.0141 \\
\hline$w_{L 1} \cdot w_{C 1}$ & $-0.0610^{* * *}$ & 0.0132 & $-0.0571^{* * *}$ & 0.0127 \\
\hline$w_{O S E 1} \cdot w_{M 1}$ & -0.0006 & 0.0033 & -0.0011 & 0.0031 \\
\hline$w_{O S E 1} \cdot w_{E 1}$ & $-0.0232^{* * *}$ & 0.0043 & $-0.0204^{* * *}$ & 0.0040 \\
\hline$w_{O S E 1} \cdot w_{C 1}$ & -0.0011 & 0.0039 & -0.0033 & 0.0035 \\
\hline$w_{M 1} \cdot w_{E 1}$ & $-0.0538^{* * *}$ & 0.0050 & $-0.0539 * * *$ & 0.0047 \\
\hline$w_{M 1} \cdot w_{C 1}$ & $-0.0265 * * *$ & 0.0047 & $-0.0309 * * *$ & 0.0041 \\
\hline$w_{E 1} \cdot w_{C 1}$ & 0.0086 & 0.0099 & 0.0070 & 0.0091 \\
\hline$C A P 1_{P}$ & - & - & - & - \\
\hline$C A P 1_{W T}$ & - & - & - & - \\
\hline Adjusted $\mathrm{R}^{2}$ & & & & \\
\hline
\end{tabular}

Notes: $\mathrm{N}=17, \mathrm{~T}=4 .^{* * *}$ : significant at 1 percent,

**: significant at 5 percent, *: significant at 10 percent. 
Table D.3: Cost function for NVI distribution utilities (Within-SURE)

\begin{tabular}{lllll}
\hline & \multicolumn{2}{c}{ SURE } & \multicolumn{2}{c}{ Iterated SURE } \\
Variable (in log) & Coef. & Std. Err. & Coef. & Std. Err. \\
\hline$Y_{2}$ & $1.0066^{* * *}$ & 0.0878 & $1.0841^{* * *}$ & 0.0466 \\
$w_{L 2}$ & 0.0246 & 0.0617 & 0.0629 & 0.0644 \\
$w_{Y_{1}}$ & $0.7056^{* * *}$ & 0.0599 & $0.7326^{* * *}$ & 0.0595 \\
$w_{O S E 2}$ & $0.1351^{* * *}$ & 0.0162 & $0.1549^{* * *}$ & 0.0170 \\
$w_{M 2}$ & $0.1489^{* * *}$ & 0.0151 & $0.1844^{* * *}$ & 0.0153 \\
$Y_{2} \cdot Y_{2}$ & 0.0278 & 0.1021 & $0.1200^{* *}$ & 0.0542 \\
$w_{L 2} \cdot w_{L 2}$ & $-2.1222^{* * *}$ & 0.5596 & $-3.0379^{* * *}$ & 0.2969 \\
$w_{Y_{1}} \cdot w_{Y_{1}}$ & $0.2857^{* *}$ & 0.1170 & $0.1488^{* *}$ & 0.1170 \\
$w_{O S E 2} \cdot w_{O S E 2}$ & 0.0270 & 0.0185 & $0.0513^{* * *}$ & 0.0621 \\
$w_{M 2} \cdot w_{M 2}$ & $0.0659^{* * *}$ & 0.0201 & $0.1081^{* * *}$ & 0.0106 \\
$w_{L 2} \cdot w_{Y_{1}}$ & $0.2952^{* * *}$ & 0.0994 & $0.5102^{* * *}$ & 0.0527 \\
$w_{L 2} \cdot w_{O S E 2}$ & -0.0078 & 0.0743 & $-0.0894^{* *}$ & 0.0394 \\
$w_{L 2} \cdot w_{M 2}$ & $0.1018^{* *}$ & 0.0482 & 0.0023 & 0.0256 \\
$w_{Y_{1}} \cdot w_{O S E 2}$ & $-0.1479^{* * *}$ & 0.0314 & $-0.1000^{* * *}$ & 0.0167 \\
$w_{Y_{1}} \cdot w_{M 2}$ & -0.0403 & 0.0264 & $-0.0403^{* * *}$ & 0.0140 \\
$w_{O S E 2} \cdot w_{M 2}$ & -0.0136 & 0.0125 & -0.0897 & 0.0066 \\
Length & 0.1366 & 0.1780 & -0.0058 & 0.0944 \\
$U_{s e r}$ & -0.2152 & 0.1529 & $-0.2764^{* * *}$ & 0.0811 \\
Rt & $-0.7484^{* * *}$ & 0.0709 & $-0.9141^{* * *}$ & 0.0376 \\
\hline Adjusted R & \multicolumn{2}{c}{0.9196} & & 0.8332 \\
\hline
\end{tabular}

Notes: $\mathrm{N}=15, \mathrm{~T}=4 .^{* * *}$ : significant at 1 percent,

${ }^{* *}$ : significant at 5 percent, ${ }^{*}$ : significant at 10 percent. 